Estimation of Nonpoint Source

Loadings of Phosphorus

for Lakes in the Puget

Sound Region, Washington

BY ROBERT J. GILLIOM 


\section{UNITED STATES DEPARTMENT OF THE INTERIOR}

WILLIAM P. CLARK, Secretary

GEOLOGICAL SURVEY

Dallas L. Peck, Director

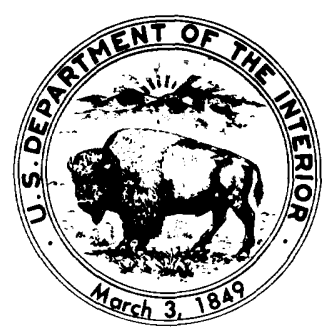

For sale by Distribution Branch

Text Products Section

U.S. Geological Survey

604 South Pickett Street

Alexandria, Virginia 22304

Library of Congress Cataloging in Publication Data

Gilliom, Robert J.

Estimation of nonpoint-source loadings of phosphorus for lakes in the Puget Sound region, Washington.

(U.S. Geological Survey water-supply paper; 2240)

Bibliography: $p$.

Supt. of Docs. No.' 1 19.13:2240

1. Eutrophication-Washington (State)-Puget Sound

Region. 2. Water-Phosphorus content. I. Title. II. Series.

$\begin{array}{llll}\text { QH96.8.E9G54 } 1982 & 628.1 ' 68 & 83-600185\end{array}$ 


\section{CONTENTS}

Abstract 1

Introduction 1

Background 1

Study area and lakes $\mathbf{3}$

Purpose and approach $\mathbf{3}$

Phosphorus as key nutrient $\mathbf{3}$

Criteria for method development 4

Two-step empirical approach 4

Estimating phosphorus loading from lake-water concentration 5

$\begin{array}{lll}\text { Phosphorus-loading relationships for different land uses } & 7\end{array}$

Reliability assessment $\mathbf{8}$

Background sources of phosphorus 9

Bulk precipitation 9

Forest-land drainage 9

Another lake in the drainage basin $\mathbf{1 0}$

Cultural sources of phosphorus

Another lake in the drainage basin $\mathbf{1 1}$

Residential area runoff $\mathbf{1 1}$

Nearshore septic tank systems $\mathbf{1 2}$

Agricultural land $\mathbf{1 6}$

Application of phosphorus-loading relationships and the lake model $\mathbf{1 6}$

General limitations $\mathbf{1 6}$

Method reliability $\mathbf{1 7}$

Typical standard errors

17

Relative reliability 18

Application I: Rating of water-quality sensitivity

Management applications

19

Procedure 19

Application II: Estimation of background phosphorus levels and cumulative impacts of development

20

Management applications

20

Procedure 20

Application III: Phosphorus loading from individual land uses

Management applications $\mathbf{2 1}$

Procedure $\mathbf{2 1}$

Summary 22

References cited $\mathbf{2 2}$

Metric conversion factors

24

\section{FIGURES}

1. Location of lakes included in this study 2

2. Relationship between phosphorus yield from forest land and annual runoff $\mathbf{1 0}$

3. Relationship between calculated phosphorus loading from nearshore septic tank system $(\Delta \mathrm{WW})$ and number of nearshore dwellings at 24 lakes in 194015 


\section{TABLES}

1. Relationships between lake-water quality and lake-water phosphorus concentration 4

2. Physical characteristics, measured mean phosphorus concentrations, and land-use data for lakes used to evaluate phosphorus loading by residential area runoff $\mathbf{1 2}$

3. Physical characteristics, measured mean phosphorus concentrations. and land-use data for 24 lakes used to evaluate phosphorus loading from nearshore septic tank systems

13

4. Number of nearshore dwellings at 24 lakes, and model-calculated phosphorus loadings from septic tank systems ( $\triangle \mathrm{WW}) \quad \mathbf{1 4}$

5. Percent standard errors in phosphorus loading estimates for 14 selected lakes evaluated by Gilliom (1982) $\mathbf{1 8}$

6. Relative reliability ratings for phosphorus-loading estimates $\mathbf{1 9}$

7. Criteria for rating lake sensitivity $\mathbf{2 0}$ 


\title{
Estimation of Nonpoint Source Loadings of Phosphorus for Lakes in the Puget Sound Region, Washington
}

\author{
By Robert J. Gilliom
}

\begin{abstract}
Control of eutrophication of lakes in watersheds undergoing development is facilitated by estimates of the amounts of phosphorus (P) that reach the lakes from areas under various types of land use. Using a mass-balance model, the author calculated $P$ loadings from present-day $P$ concentrations measured in lake water and from other easily measured physical characteristics in a total of 28 lakes in drainage basins that contain only forest and residential land. The loadings from background sources (forest-land drainage and bulk precipitation) to each of the lakes were estimated by methods developed in a previous study. Differences between estimated present-day $P$ loadings and loadings from background sources were attributed to changes in land use. The mean increase in annual $P$ yield resulting from conversion of forest to residential land use was 7 kilograms per square kilometer, not including septic tank system contributions. Calculated loadings from septic systems were found to correlate best with the number of nearshore dwellings around each lake in 1940 . The regression equation expressing this relationship explained 36 percent of the sample variance. There was no significant correlation between estimated septic tank system P loadings and number of dwellings present in 1960 or 1970 . The evidence indicates that older systems might contribute more phosphorus to lakes than newer systems, and that there may be substantial time lags between septic system installation and significant impacts on lake-water $\mathbf{P}$ concentrations. For lakes in basins that contain agricultural land, the $\mathbf{P}$ loading attributable to agriculture can be calculated as the difference between the estimated total loading and the sum of estimated loadings from nonagricultural sources. A comprehensive system for evaluating errors in all loading estimates is presented. The empirical relationships developed allow preliminary approximations of the cumulative impact development has had on $P$ loading and the amounts of $P$ loading from generalized land-use categories for Puget Sound lowland lakes. In addition, the sensitivity of a lake to increased loading can be evaluated using the mass-balance model. The data required are presently available for most lakes. Estimates of $P$ loading are useful in developing waterquality goals, setting priorities for lake studies, and designing studies of individual lakes. The suitability of a method for management of individual lakes will often be limited by relatively high levels of uncertainty, especially if the method is used to evaluate relatively small increases in P loading.
\end{abstract}

\section{INTRODUCTION}

\section{Background}

Excessive enrichment of lakes by plant nutrients is a widespread problem for both urban and rural lakes in the Puget Sound region (fig. 1) and elsewhere. Increased nutrient loading (input) to a lake as a result of human activity has come to be known as "cultural eutrophication." The high levels of nutrients commonly associated with cultural eutrophication can quickly lead to undesirable growth of algae and other aquatic plants, and to many related water-quality problems. Some key related problems, such as murky water, floating scum, and depletion of dissolved oxygen, greatly inhibit uses of a lake for recreation and water supply. Fortunately, eutrophication of lakes can be substantially cont rolled (most successfully by reducing nutrient loading), but the necessary lakemanagement actions are complicated by several factors.

One complicating factor is that of overlapping management jurisdictions and divergent responsibilities. For example, the management of lake levels and inflowing streams may be the responsibility of a State waterregulation agency, whereas the regulation of lake-water quality may involve public health and environmental agencies at various levels of government. Moreover, lakewater quality is complexly related to land uses within the lake's drainage basin (and, for airborne contaminants. even beyond the drainage divides), while land-management responsibilities usually are vested in an agency (commonly at county level) that does not manage the water. These divergent responsibilities greatly weaken the incentive and ability of any one agency to collect the data needed to fully assess deterioration of lake quality and to manage a lake efficiently, even should the necessary funds and expertise be available.

Another factor is the widespread scope of lakequality deterioration caused by the rapid development of lake shores and lake basins for agricultural land and homesites. Such development has both immediate and delayed effects on lake waters. The continuously increasing problem has, on one hand, created increasing demands for regulation of lake-water quality, and, on the other 


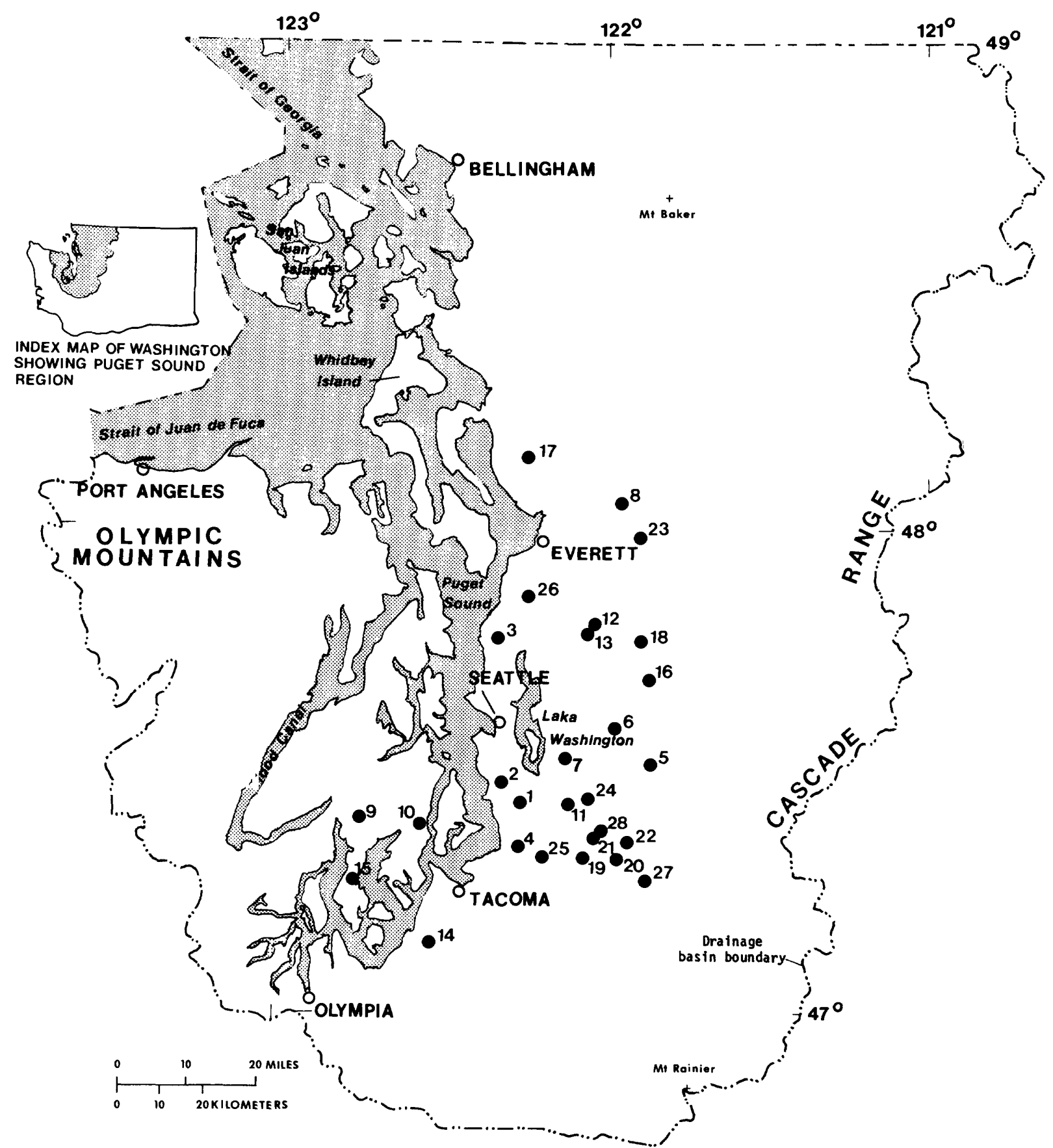

Figure 1. Location of Puget Sound region lakes included in this study. Numbers refer to listings of the lakes in tables 2 and 3.

hand, greatly overtaxed the abilities of regulatory agencies to collect the necessary data and meet the demands for evaluation and regulation.

A third factor is the complexity of the hydrologic systems through which water and associated contaminants enter and leave the lakes. This complexity often masks the true sources of lake-water contaminants and can foil lake-management schemes that are based only on the obvious cause-and-effect relationships.

A fourth complicating factor, which is crucial to all the other factors mentioned, has been the lack of a sound method for rapidly gaining a perspective of the unique cause-and-effect relationships between lake-water quality and local land uses for individual lakes. This perspective is crucial in identifying which lakes might benefit most from the application of limited resources for inves- 
tigation and management, and in deciding how to assess each lake. This report presents such a method. and describes its appropriate uses and the uncertainties inherent in its use.

\section{Study Area and Lakes}

The Puget Sound region ( fig. 1) includes more than 500 lakes, which have a wide range of nutrient levels and land-use settings. The large number and increasing use of lakes in this region, and the rapid land development around them, make evaluation and control of cultural eutrophication a pressing and difficult task for local and State agencies.

Most lakes in the Puget Sound lowland occupy depressions in glacial till or out wash deposited during the most recent continental glaciation. Soils surrounding the lakes are mainly shallow, gravelly sandy loams with local deposits of peat, muck, and fine-textured material (silt to clay). Native vegetation consisted predominantly of dense growths of conifers. but most merchantable timber has been harvested at least once. resulting in a mixed forest containing both conifers and deciduous trees.

The Puget Sound region has a mild maritime climate characterized by cool, wet winters and warm. fairly dry summers. Average annual precipitation in the lowland part of the region ranges from 0.2 to $2.0 \mathrm{~m}$. depending on altitude and location relative to the Olympic Mountains and the Cascade Range. About 80 percent of the precipitation occurs from October through April. Field observations and inference from discharge records of gaged streams indicate that lowland lakes in the region receive most of their inflow during the winter season. even though the lakes are scattered among localities with wide variations in annual runoff.

Surface-water inflow to lowland lakes is generally intermittent and is mainly confined to the winter season. lce cover is rare in these lakes (and brief when it occurs) and most of them are evenly mixed from fall until the onset of thermal stratification during the summer. Thermal stratification results in a warm upper layer of water, termed the epilimnion, overlying distinctly cooler water trapped underneath. which is termed the hypolimnion. Thermal stratification in the lakes commonly begins in May and persists through September or early October. In most lakes with a mean depth greater than $3 \mathrm{~m}$ the stratification is stable during the summer.

Data for 28 lakes were used in this study and data for 24 additional lakes were used in an earlier. related study (Gilliom, 1981) which is summarized in this report. The locations of the 28 lakes used for this study are shown in figure 1. Lake data, values for model terms, and measured total $P$ concentrations for the 28 lakes are later given in tables 2 and 3 . All 28 lakes appear to attain stable thermal stratification during the summer. Although Alice Lake has a mean depth less than $3 \mathrm{~m}$ (table 3 ). the water in the main basin of the lake is deeper and stratifies.

\section{PURPOSE AND APPROACH}

Controlling eutrophication usually requires reduction of nutrient loading by land-use management, which is most effective when based on quantitative evaluation of nut rient sources and their impacts on lake-water quality. However, detailed studies of nutrient sources, loadings, and impacts for a particular lake are time-consuming and expensive, and usually are practical for only a few lakes owing to previously discussed agency constraints. Efficient use of agency resources for lake evaluation is, therefore. very desirable. Such efficiency requires that "problem" lakes be recognized as early as possible, that water-quality goals be realistic, and that specific lake studies be particularly well designed. For assigning priorit ies, forming goals, and designing detailed studies, preliminary assessments of nonpoint sources of nutrients and their impacts on lake-water quality are needed. Preliminary assessments can help identify lakes with severe or potential water-quality impacts associated with human activities and help guide further studies by showing which nutrient sources are probably most important.

The purpose of this report is to describe a newly developed approach for making preliminary evaluations of the effects of land-use changes on lake-water concentrations and nonpoint source loadings of the key nutrient, phosphorus, for Puget Sound region lakes.

\section{Phosphorus as Key Nutrient}

Phosphorus ( $\mathrm{P})$ is generally considered to be the growth-limiting and most controllable nutrient involved in algal productivity in lakes (Vollenweider, 1968: Schindler and Fee, 1974; Schindler, 1977: R ast and Lee, 1978: and Schindler, 1978). The concentration of $P$ in lake water is the most commonly used criterion to classify a lake's rate of eutrophication (Rast and Lee. 1978). There is a strong correlation between total $P$ concentrations in lakes and chlorophyll $a$ concentrations. which are related to the concentration of algae in lake water (Sakamoto. 1966; Dillon and Rigler, 1975; Jones and Bachmann. 1976: and Vollenweider, 1976). Moreover, total P and chlorphyll $a$ concentrations can be quant it atively related to water clarity, as measured by Secchi-disk transparency (see Rast and Lee. 1978, for several examples). and to dissolved-oxygen depletion (Rast and Lee. 1978: Welch and Perkins, 1979; and Walker, 1980). These waterquality characteristics reflect the general suitability of a lake for various uses (Dillon and Rigler, 1975). For most lakes, if the mean total $P$ concentration is known, then 
much is also known about the general quality of the lake. General relationships between total $P$ concentrations and lake-water quality are shown in table 1 . Table 1 relates water quality to the average concentration in a lake's epilimnion during the summer. These relationships between $P$ levels and water-quality factors provide the basis for using $\mathbf{P}$ concentrations as a main indicator of lake quality.

\section{Criteria for Method Development}

Although the concentration of phosphorus in a lake is determined by many physiccal, hydrologic, biological, and chemical factors, loading is the most common determinant of concentration that is altered by human activities. The main goal of this study was to develop a method for estimating loadings that would be useful to water-quality managers within their fiscal and time constraints. The study approach was heavily influenced by the practical factors that affect the use of such methods in the real world setting of environmental management.

On the basis of the considerations outlined in the "Background" section, as well as discussions with local water-quality managers, the following criteria were set to guide method development and presentation:

1. Because of constraints on funding and manpower resources, the method had to be developed from data that were already available.

2. The method should also rely mainly on available data for application and require little time to use.

3. The method should be applicable to the majority of lakes in the Puget Sound region.

4. The reliability of each part of the method should be evaluated to the fullest extent possible so that the user of information from the method can realistically judge the value of estimates.

5. Even parts of the method that seem somewhat unreliable, or whose reliability is difficult to assess, should be presented and discussed. These parts may produce the best available information of the kind that the decisionmaker needs.

6. The best means of using the method to evaluate nonpoint source $P$ loadings and their impacts on lakewater concentrations should be summarized in a stepby-step manual format.

\section{Two-Step Empirical Approach}

The method used in this study was to establish empirical relationships between estimated annual loadings of phosphorus to Puget Sound region lakes and the different types of land uses (nonpoint P-loading sources) in the drainage basins of the lakes. "Empirical" means

Table 1. Relationships between lake-water quality and lake-water phosphorus concentration [Modified for the Puget Sound region from Dillon and Rigler, 1975]

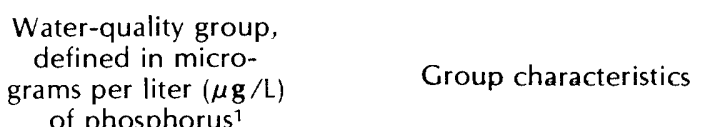

A

$(0-10)$

B

$(10-20)$

C

D

(greater than 30)
Low algal productivity; high suitability for all recreational uses. Algal blooms are rare and water is extremely clear. with a Secchi-disk visibility ${ }^{2}$ that is usually $5 \mathrm{~m}$ or greater. Summer chlorophyll $a$ concentrations generally average less than $3 \mu \mathrm{g} / \mathrm{L}$.

Moderate algal productivity; generally compatible with all recreational uses. Algal blooms are occasional, but generally of low to moderate intensity. Oxygen depletion is common in bottom waters and cold-water fisheries may be endangered in some shallow lakes. In many lakes, however, fishery may be enhanced by increased productivity. Secchi-disk visibility is usually 3 to $5 \mathrm{~m}$; chlorophyll $a$ averages 2 to $6 \mu \mathrm{g} / \mathrm{L}$ in most lakes.

Moderately high algal productivity; still compatible with most recreational uses, but algal blooms are more frequent and intense, and oxygen deletion is more serious. This can increase fisheries problems, though productivity may still be enhanced. Water clarity is reduced and Secchi-disk visibility is usually 2 to $4 \mathrm{~m}$. Chlorophyll $a$ averages 4 to $\mathrm{I} 0 \mu \mathrm{g} / \mathrm{L}$.

High algal productivity; lake suitability for most recreational uses is often impaired by frequent and intense algal blooms which may form floating scums. The water often takes on a "pea soup" color and becomes extremely murky. Fish kills may be common, especially in shallow lakes. Secchi-disk visibility is generally less than $3 \mathrm{~m}$, and chorophyll $a$ concentration is usually greater than $10 \mu \mathrm{g} / \mathrm{L}$.

IAverage total $\mathrm{P}$ measured in epilimnion waters during the summer season.

2Depth to which one can see a 20 -cm-diameter black-and-white disk through the water.

based on practical experience rather than theory. Establishing empirical relationships usually means that statistical relationships are developed between apparent causes 
(land uses) and their observed effects ( $P$ concentration or loading) rather than trying to simulate the physical, biological, and chemical processes that truly govern the cause-effect relationship. Theoretical approaches generally require much detailed information, and they commonly are not practical either to develop or use unless the detailed understanding of a particular environmental system provides very great potential benefits.

The development of relationships between land uses and loadings, which are discussed in detail in the following two report sections, proceeded in two main steps.

1. First, an approach was developed for calculating annual $P$ loadings to lakes using available data on measured lake-water concentrations.

2. Annual loadings were then calculated for selected lakes and evaluated for their relationship to different landuse-related sources of $P$ in lake-drainage basins. This process led to empirical relationships between land uses and $\mathbf{P}$ loadings that can be used to estimate loadings from selected major types of land use for Puget Sound region lakes.

The resulting relationships allow use of data already available for most lakes in this region to assess (1) a lake's sensitivity to changes in $P$ loadings, (2) the cumulative impacts of drainage-basin land uses on $P$ concentrations and loadings relative to background (predevelopment) conditions, and (3) the contribution of individual landuse types to increases in $\mathbf{P}$ loading. This study uses and summarizes findings from a previous study (Gilliom, -1981) that evaluated background $P$ concentrations and loadings. The derivation of relationships between developed land uses and $\mathrm{P}$ loadings is described in detail; methods for assessing the reliability of estimates from the relationships are also presented. The details of method development are followed by a step-by-step discussion of how to apply the methods for water-quality management.

This report does not include extensive examples of method application; however, in a companion study (Gilliom, 1983) the method was used for a regional analysis of eutrophication that involved 29 lakes. The report of that study (in map format) is a prototype of how the methods described in the present report can be applied and the results displayed.

\section{ESTIMATING PHOSPHORUS LOADING FROM LAKE-WATER CONCENTRATION}

There are several simple models that were designed for estimating the concentration of total phosphorus in a lake from its annual loading (see for examples Dillion, 1974; R ast and Lee, 1978). One model, originally developed by Piontelli and Tonolli (1964) and refined by
Vollenweider (1969; 1976) and Dillon and Rigler (1975), has consistently produced accurate results in different areas of North America (Larsen and Mercier, 1976; Rast and Lee, 1978). The same model has also been successfully used in slightly modified form in the Puget Sound region (Gilliom. 1978). The general model may be written as

$$
(\bar{P})_{\infty}=\frac{L \cdot(1-R)}{\overline{\mathrm{z}} \cdot A \cdot \rho}
$$

where

$(\bar{P})_{\infty}=$ mean concentration of total $\mathrm{P}$ at steady state (constant long-term average) in the lake, in micrograms per liter $(\mu \mathrm{g} / \mathrm{L})$;

$L=$ the total $-P$ loading to the lake, in kilograms per year $(K g / y r)$;

$R=$ the lake-retention coefficient (decimal percentage of $L$ retained in the lake, but not causing an increase in total-P concentration), dimensionless;

$\overline{\mathrm{z}} \quad=$ mean depth, in meters;

$A=$ lake surface area, in square kilometers $\left(\mathrm{km}^{2}\right)$;

and

$\rho=$ lake-flushing rate, in times per year that a volume of water equal to the lake's volume flows through the lake.

In plain terms, the model states that the average $P$ concentration in a lake is determined by the amount of $\mathbf{P}$ loading to the lake, less those amounts of loading lost by sedimentation and lake outflow, diluted by the volume of water in the lake. It is a simple, mass-balance accounting model.

Larsen and Mercier (1976) and Vollenweider (1976) independently found that $R$ can be approximated by

$$
R=\frac{1}{1+\sqrt{\rho}} .
$$

Flushing rate can be estimated from

$$
\rho=\frac{W S A \cdot R O}{\overline{\mathrm{z}} \cdot A},
$$

where $W S A$ is watershed area, including lake surface, in square kilometers, and $R O$ is average annual runoff, in meters. Runoff depth here refers to statistical estimates of runoff based on observed streamflow from many watersheds in this region (see tables 2 and 3). Therefore, these estimates include water reaching lakes by inflowing streams, overland flow (sheet runoff), and ground water (including subsurface stormflow or ephemeral ground water). For lack of better information, the net balance of water exchange at the lake surface (precipitation less 
evaporation) is implicitly approximated in equation 3 by the rate of annual runoff in the locality of the lake because lake area is included in the term WSA. The author found that this approach was acceptable for most Puget Sound region lakes (Gilliom, 1978).

Assumptions required to apply the mass-balance model have been reviewed by other authors such as DilIon (1974) and Vollenweider (1969; 1976). These assumptions were found to be generally valid, or not a significant problem, for most lakes in the Puget Sound lowland (see Gilliom, 1978, for detailed discussion).

In the absence of data on measured $P$ loadings to a lake (seldom available), loading can be estimated from lake-water $\mathbf{P}$ concentrations using the mass-balance model. Equation 1 can be arranged as follows:

$$
L=\frac{(\bar{P})_{\infty} \cdot \overline{\mathrm{z}} \cdot A \cdot \rho}{(1-R)}
$$

If $(\bar{P})_{\infty}$, the mean concentration for an entire lake, were known from measurements, the mean annual loading of total $P$ to the lake could be estimated from equation 4 . This approach to estimating loading is advantageous because mean concentrations of total $P$ in lake water are far easier and less expensive to measure than $P$ loadings. In effect, the lake is used as a time-integrated sampler of $\mathbf{P}$ loadings.

If the value of $(\bar{P})_{\infty}$ cannot be determined, it can be replaced with a different estimate of $\mathbf{P}$ concentration based on data that are easier to obtain or already exist (for example, winter-spring P or summer epilimnion P), provided a consistent proportional relationship exists between $(\bar{P})_{\infty}$ and the alternate concentration term. The loading term, $L$, however, must be carefully redefined if such a substitution is made. For this region, substitution of mean epilimnion total $\mathbf{P}$ during the summer instead of $(\bar{P})_{\infty}$ would be advantageous. Such concentrations are better correlated with summer algal growth and lakewater transparency than other concentration terms (Gilliom and Bortleson, 1983), and many more data are available for summer epilimnion concentrations.

Such a substitution appears to be valid for Puget Sound region lakes because there are relatively consistent proportional relationships between annual, summer, and winter-spring $\mathbf{P}$ levels in epilimnion waters. Data for 10 intensively studied lakes in the region (Gilliom, 1981) indicate that summer epilimnion total $P$ averages 89 percent of the annual mean for near-surface waters $\left(\mathrm{r}^{2}=0.88\right)$ and 75 percent of winter-spring $P\left(r^{2}=0.69\right)$. The annual mean concentration of total $P$ for an entire lake should be somewhat higher than the annual mean concentration in near-surface waters because of generally high hypolimnion concentrations during the summer. Unfortunately, data for this region's lakes are not adequate to directly evaluate this effect. Chapra and Tarapchak (1976) found, for a number of lakes in different parts of North A merica, that annual mean total $\mathbf{P}$ for an entire lake averages about 90 percent of the spring total $P$, and that these two $P$ concentrations are highly correlated. That finding, combined with the aforementioned relationship between summer total $P$ and winter-spring total $P$, indicates that summer epilimnion total $P$ probably averages about 83 percent of annual mean total $P$ for the entire lake. Though the precise proportional relationship will vary between individual lakes, the high correlation between different types of mean $P$ concentrations within the region suggests that loadings may be evaluated just as accurately from summer epilimnion mean concentrations as from any other. Any errors that may result from applying this conclusion, in any event, are later implicitly accounted for as part of the statistically evaluated uncerrainty in the loading-estimation methods.

Phosphorus loadings for the lakes studied were, therefore, calculated from the mean total $P$ concentration in a lake's epilimnion during the summer. Equation 4 was modified to be

$$
L^{*}=\frac{(\bar{P})_{\mathrm{Ss}} \cdot \overline{\mathrm{z}} \cdot A \cdot \rho}{(1-R)},
$$

or

$$
(\bar{P})_{\mathrm{SS}}=\frac{L^{*} \cdot(1-R)}{\overline{\mathrm{z}} \cdot A \cdot \rho}
$$

where $(\bar{P})_{\text {ss }}$ represents the mean steady-state concentration of total $P$ in the epilimnion of a stratified lake during the summer, in micrograms per liter, and $L^{*}$ is an empirically derived $\mathbf{P}$ loading rate, in kilograms per year, described shortly. Alternatively, one could convert values of $(\bar{P})_{\text {ss }}$ to values of $(\bar{P})_{\infty}$ (using their estimated proportional relationship) and then use equation 4 to estimate the total P loading of the lake. This would be a useful approach for deriving total $P$ loading estimates for comparison to measured loadings. However, more important for the purposes of this study is an accurate assessment of the relationship between summer epilimnion total $P$ and sources of $\mathbf{P}$ loading. Complicating the assessment with additional empirical relationships would simply compound the possibilities for error. All loading values evaluated in this report are thus defined in relation to empirically estimated $P$ loading described below. Hereafter, all $\mathbf{P}$ concentrations refer to mean total $\mathbf{P}$ concentrations in a lake's epilimnion during the summer, unless noted otherwise.

Phosphorus loading rates, $L^{*}$, calculated by equation 5 are not equivalent to total $\mathrm{P}$ loading ( $L$ in eq 1$)$ and, therefore, are not freely interchangeable with values of $L$. The values of $L^{*}$ and $L$ could theoretically be equal only 
if $(\bar{P})_{\text {ss }}$ and $(\bar{P})_{\infty}$ were equal, which is generally not the case. Equation 1, as mentioned earlier, was derived from, and is usually used for, an evaluation of the average annual total $\mathrm{P}$ budget of a lake, on a whole-lake basis. Equation 5, in contrast, relates $\mathrm{P}$ loading to the summer epilimnion concentration. which is generally about 17 percent smaller than the average whole-lake concentration for the entire year. Therefore, $L^{*}$ is expected to average about 17 percent less than the actual total $P$ loading to a lake.

The factor $\frac{1-R}{\overline{\mathrm{z}} \cdot A \cdot \rho}$ is a constant for a particular lake because it is comprised of the unchanging average values for lake depth, area, flushing rate, and the retention coefficient. Therefore, equations 5 and 6 can be expressed in abbreviated form as

$$
L^{*}=\frac{(\bar{P})_{\text {ss }}}{S}
$$

and

where

$$
(\bar{P})_{\mathrm{SS}}=S \cdot L^{*},
$$

$$
S=\frac{1-R}{\overline{\mathrm{z}} \cdot A \cdot \rho},
$$

and $S$ is termed the "lake-sensitivity coefficient." Once $S$ is calculated for a lake, further calculations of loading or concentration are easier, and the value of $S$ can be used to rate lakes based on their relative sensitivity to increased $P$ loadings. The value of $S$ is simply the predicted change in $(\bar{P})$ ss that would be caused by a l-kilogram change in annual average $P$ loading. A pplication of sensitivity coefficients to the rating of lakes is discussed later.

Note that the use of equation 5 or 7 incorporates errors in all terms in the right-hand side of the equation, as well as model error, in the calculated values of $L^{*}$. For simplicity, model error and errors in all terms used to calculate $S$ can be considered to result in a net error in $S$. This error is independent of errors in $(\bar{P})$ ss. The problem of estimating the uncertainty in predicted values of $L^{*}$ based on uncertainties in $S$ and $(\bar{P})_{\text {Ss }}$ is addressed in the following section.

\section{PHOSPHORUS-LOADING RELATIONSHIPS FOR DIFFERENT LAND USES}

Specific sources of the loading of phosphorus to a lake were considered in two categories: background (predevelopment) sources, and cultural (human-related) sources. Only nonpoint sources were evaluated because point sources are not a problem for most lakes in the Puget Sound region, and point sources are not difficult to assess on a case-by-case basis if necessary. Background $\mathbf{P}$ sources consist of (1) water draining from the forested (undeveloped) parts of a lake's immediate drainage basin (the part containing no other lakes), (2) bulk precipitation (both rainwater and dry fallout) directly on a lake's surface, and (3) possible loadings from the outflow of an upstream lake.

The main focus of this study was on cultural sources, which were evaluated according to the general categories of residential and agricultural land use. Phosphorus loading from residential areas was considered to have two components: naturally derived water running off the residential area (hereafter referred to as residential area runoff), and seepage from septic tank systems. In addition, the influence of human-related increases in loading from upstream lakes was assessed. All these cultural sources were evaluated according to the increases above background loading levels that they produce.

In mathematical terms, phosphorus loading to a lake, as defined above, can be described as follows:

$$
\begin{aligned}
L^{*}= & (P R E L \cdot A)+\left(F O R Y \cdot W S A_{\mathrm{bg}}\right)+U P+ \\
& \Delta U P+\Delta R R+\Delta W W+\Delta A G,
\end{aligned}
$$

where

PREL

FORY

$=$ the areal rate of lcading by precipitation, in kilograms per square kilometer per year:

$=$ the yield of forested areas, in kilograms per square kilometer per year;

$W S A_{\mathrm{bg}}$

$=$ the area of land in the lake's drainage basin from which runoff does not pass through another lake before reaching the subject lake, in square kilometers;

$U P$

= the background loading from an upstream lake, in kilograms per year;

and

$\triangle U P, \triangle R R, \triangle W W$, and $\triangle A G$

= incremental increases in loading above background levels attributable, respectively, to increased $P$ levels in upstream lakes, residential area runoff, nearshore septic tank systems, and agricultural land, in kilograms per year. 
The evaluation of each loading and yield term is described subsequently. The reliability of the method for assessing background loading is fairly high and relatively well defined: derivation of the method is only summarized in this report (see Gilliom, 1981, for more detail). The reliability of the evaluation of cultural sources is both lower and more difficult to accurately assess. Derivation of methods for assessing these sources and the reliability of estimates are discussed in detail. The validity of P-loading relationships developed in this study is demonstrated mainly by statistical measures of significance and reliability based on the groups of lakes studied. Also, for residential area runoff and nearshore septic tank systems, $\mathbf{P}$ loadings estimated by the methods developed are compared to general ranges of published values from other studies.

There were no independent sets of lakes against which to test the relationships developed in this study. because all suitable data available were used to develop the empirical relationships. The decision to use all the data in method development was made largely because a preliminary P-loading assessment, using similar techniques (Gilliom, 1978), was successfully validated on an independent sample of 20 lakes having a wide variety of land-use conditions. In that study, predicted lake-water $P$ concentrations based on relationships between land uses and loading were compared to observed concentrations for the independent sample; and the standard error of prediction was 35 percent.

The methods developed in this report should be considered an initial step in the model-development process. Ideally, this development process should proceed incrementaly as the need for information and the availability of data increase. It should provide the best methods for estimating loading that our current level of knowledge allows, within practical constraints such as time and money. More concentration data for lakes, and the gradual accumulation of detailed P-loading studies in the future, will provide the information necessary to further test the methods, improve the relationships, and reduce uncertainty.

\section{Reliability Assessment}

Every estimate of average concentration and loading of phosphorus, whether derived from measured data or an empirical relationship, has some degree of uncertainty associated with it. That is, the true mean value is not known. This uncertainty results from natural variability in lake systems (and any natural system), measurement errors, and errors in models, or empirical relation- ships, used to characterize the lake system. For some estimates, the uncertainty is easy to evaluate, but for others, it is difficult. One way to express uncertainty is by standard errors of estimates, hereafter referred to as standard errors. A standard error specifies a confidence interval around an estimated mean value that has a specified probability (level of chance) of including the true mean value.

In this report, a standard error always defines the 68 -percent confidence interval. The interval is expressed as a plus-or-minus standard error value. For example, an estimated mean $\mathrm{P}$ loading of $10 \pm 3 \mathrm{~kg} / \mathrm{yr}$ would signify that there is a 68 -percent probability or about a $2 / 3$ chance that the true mean lies within the range of 7 to 13 $\mathrm{kg} / \mathrm{yr}$. In general, there is also an 84-percent probability that the true mean is greater than the estimated mean minus the standard error (greater than 7 in the example cited). or that the true mean is less than the estimated mean plus the standard error (less than 13 in the example).

The use of standard errors as described above is not without problems. First, one must assume that there is an equal chance of underestimating or overestimating a particular mean and that the potential for error is normally distributed. This assumption clearly does not work, for example, when estimated $P$ loading from a particular land use has a standard error of more than 100 percent. Such a standard error cannot mean that the land use may have a negative loading. It may mean, however, that one cannot make a strong conclusion concerning whether that loading is significantly greater than background loading. In general, background loading rates are a lower practical limit; thus the minus-side potential for error is 100 percent or less. When standard errors indicate a range of loading that is completely above background loading, it must be assumed that the potential for error is similar both above and below the estimated mean because, at the level of this study, more detailed knowledge is not available.

A nother problem with reliance on standard errors is that they are often difficult to assess. Not making such an assessment, however, is to avoid evaluating the worth of the estimated value of the mean. The approach taken in this study, therefore, was to make the fullest attempt to provide a procedure for estimating standard errors of all concentration and loading estimates. Some of the procedures are admittedly not rigorous, but they provide estimates that are better than none, and they outline a framework for assessing errors that can be improved in the future as we learn more about the distributions of possible errors. Standard errors of estimates for terms calculated as the sums of other terms were evaluated using relationships for propagating independent errors described by Meyer (1975), unless noted otherwise. 


\section{Background Sources of Phosphorus}

This section describes the derivation of relationships necessary for estimating the background loading of phosphorus to a lake. For lakes with no significant development in their drainage basins, equation 10 reduces to

$$
L_{\mathrm{bg}}^{*}=(P R E L \cdot A)+\left(F O R Y \cdot W S A_{\mathrm{bg}}\right)+U P,
$$

where $L_{\mathrm{bg}}^{*}$ is the loading from background sources as calculated from the measured $P$ concentration in a lake using equation 7 . To evaluate background loading, data for lakes with no other lakes in their drainage basins were used. Given data to determine $L_{\mathrm{bg}}^{*}, A$, and $W S A_{\mathrm{bg}}$, there were two unknowns, $P R E L$ and $F O R Y$, in equation 11 . To solve the equation for $F O R Y$ for individual lakes, a regional average value of $P R E L$ was first determined independently.

\section{Bulk Precipitation}

Phosphorus loading by bulk precipitation, PREL, was determined from data already available for the study area. Data reported by Ellsworth and Moodie (1964) for two stations in the Puget Sound lowland indicate that $P R E L$ is approximately $20\left(\mathrm{~kg} / \mathrm{km}^{2}\right) / \mathrm{yr}$ (eq 12$)$, and this was assumed to be a constant for the study area.

$$
P R E L=20 \text {. }
$$

The limited data did not allow a meaningful evaluation of the degree of uncertainty associated with this estimate, but it is subsequently included as a source of uncertainty in estimates of loading from forest land.

\section{Forest-Land Drainage}

The yield from forest land, FORY, can be calculated by difference for any lake with a forested, undeveloped drainage basin using equation 13 .

$$
F O R Y=\frac{L_{\mathrm{bg}}^{*}-(P R E L \cdot A)}{W S A_{\mathrm{bg}}} .
$$

FOR $Y$ was calculated for 24 such undeveloped lakes with no other lakes in their drainage basins. Values of FORY for these lakes were found to be highly correlated with annual runoff in the vicinities of the lakes. The following regression equation, which explained 73 percent of the sample variance, can be used to estimate FOR $Y$ for any lake that is in a locality of the Puget Sound region and has an annual runoff approximately in the range of 0.1 to 1.5 $\mathrm{m}$.

$$
F O R Y=7.1 \cdot \ln R O+16.6 \text {, }
$$

where all symbols are as previously defined. For estimating FORY for lakes in low runoff areas, a yield of 1 $\left(\mathrm{kg} / \mathrm{km}^{2}\right) / \mathrm{yr}$ (the lowest value calculated for the 24 lakes) should be used if the regression equation produces a value lower than 1 .

The solution to equation 14 and confidence limits for estimates of FOR $Y$ are given in figure 2. The average standard error of estimate of FORY (SE $\left.E_{\mathrm{FORY}}\right)$ for individual lakes is about $3.6\left(\mathrm{~kg} / \mathrm{km}^{2}\right) / \mathrm{yr}$ and this varies little with runoff. Thus, for lakes in low-runoff areas, the percent standard error is large. For most lakes in the region, however, the standard error of FORY averages about 25 percent.

With estimates of PREL and FORY, the total background loading of $P$ for a developed lake can be calculated using equation 11 provided the lake receives no inflow from another lake. The standard error of this estimated background loading can be calculated using equation 15 .

$$
S E_{L_{\mathrm{bg}}^{*}}=S E_{\mathrm{FORY}} \cdot W S A_{\mathrm{bg}},
$$

where $S E_{L_{\mathrm{bg}}^{*}}$ is the standard error of the loading estimate.

To use equation 15 , one must assume that all uncertainty in a calculated value of $L_{\mathrm{bg}}^{*}$ is due to uncertainty in estimated loading from forest land. This is not strictly true, but the uncertainty in values of FORY from equation 14 is the result of the combined variability in all model terms (including $(\bar{P})_{\text {ss }}$ and $P R E L$ ) and model error. The uncertainty in all model terms and in the lake model is, therefore, incorporated in estimates of standard errors in FOR $Y$ from the regression equation. Thus, the above method is generally valid for approximating standard errors of background loading.

The uncertainty associated with estimates of background loadings calculated by the above method is less than the uncertainty that should have resulted from errors in the lake-water $P$ concentrations in the undeveloped lakes, which were typically \pm 30 to \pm 50 percent (these errors are described in Gilliom, 1981). This implies that the uncertainty in lake-water $P$ concentrations was overestimated (the errors were only approximated by a method described by Gilliom, 1978, because of the few measurements available) and that model error, referring, in this instance, to the combination of errors in the conceptual model and all model terms used to compute the sensitivity coefficient (eq 9), is fairly small. Based on first-order uncertainty analysis and an assumed value for the true error in lake-water $P$ concentrations of \pm 15 percent for the undeveloped lakes, the standard error of 


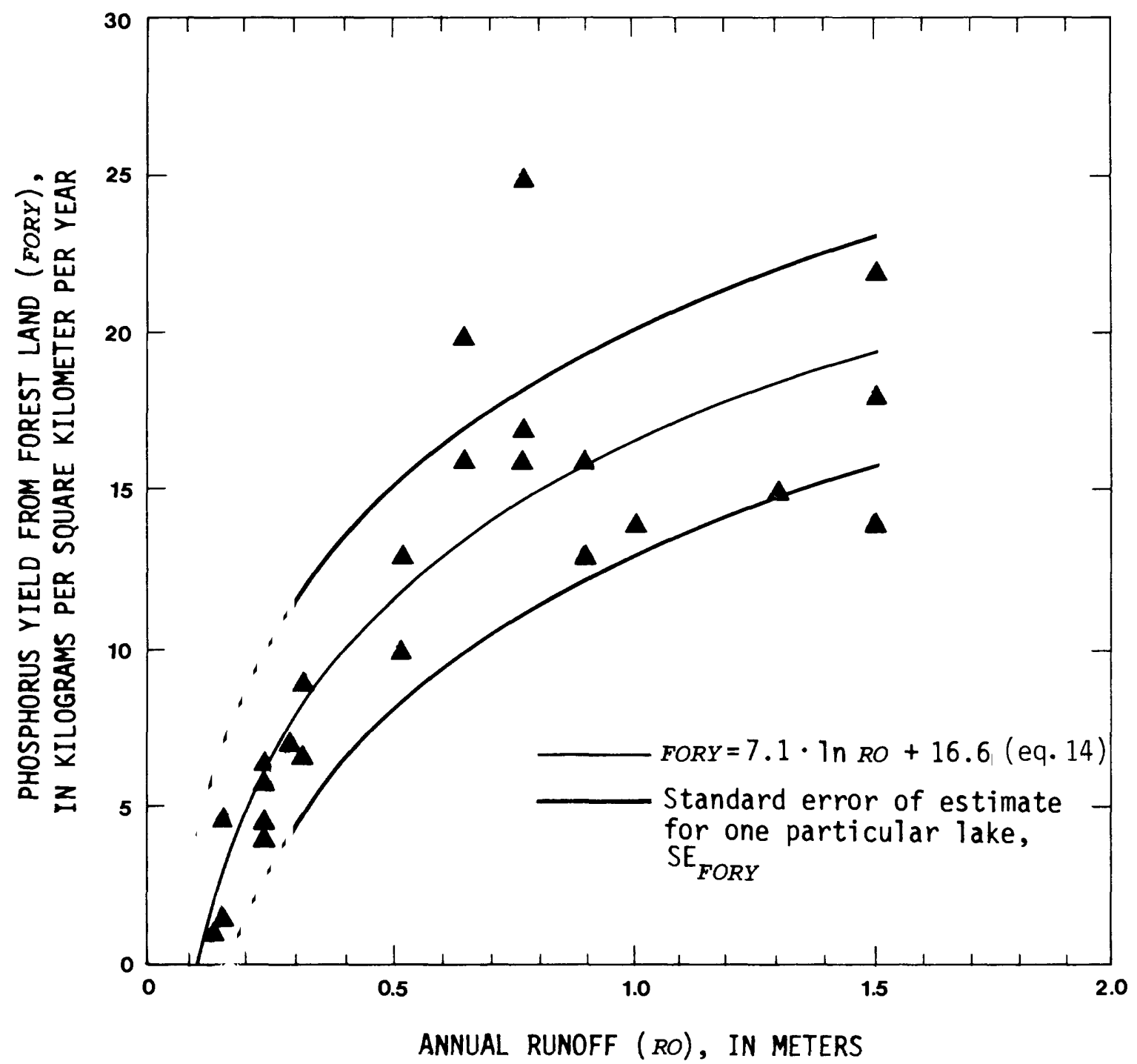

Figure 2. Relationship between phosphorus yield from forest land and annual runoff (Gilliom, 1981)

the model appears to be about \pm 20 percent, expressed as a percentage of $S$. This is believed to be a conservatively high estimate of the standard error in $S$, because a higher assumed error in $\mathbf{P}$ concentration, which is likely, results in a smaller error in $S$.

\section{Another Lake in the Drainage Basin}

If the out let stream from another lake flows into the lake being evaluated, the $P$ loading from the watershed of the upstream lake needs to be treated as a separate source, $U P$, because the upstream lake acts as a partial $\mathrm{P}$ trap. The value of $U P$ is estimated by calculating $L_{\mathrm{bg}}^{*}$ by equation 11 for the upstream lake and decreasing it according to the lake-retention coefficient, $R$, for the upstream lake.

$$
U P=L_{\mathrm{bg}}^{*} \cdot(1-R),
$$

where $L_{\mathrm{bg}}^{*}$ and $R$ are values for the upstream lake. The standard error of $U P\left(S E_{\mathrm{UP}}\right)$ can then be approximated by

$$
S E_{\mathrm{UP}}=S E_{L_{\mathrm{bg}}^{*}} \cdot(1-R),
$$

where $S E_{L_{\mathrm{bg}}^{*}}$ is calculated by equation 15 for the upstream lake. 
The standard error of an estimated background loading by equation 11 is then

$$
S E_{L_{\mathrm{bg}}^{*}}=\left[\left(S E_{\mathrm{FORY}} \cdot W S A_{\mathrm{bg}}\right)^{2}+S E_{\mathrm{UP}^{2}}\right]^{1 / 2} .
$$

\section{Cultural Sources of Phosphorus}

Cultural sources of phosphorus can now be assessed by evaluating the difference between background loading and present-day loading. Equation 6 can be rewritten as

$$
L^{*}=L_{\mathrm{bg}}^{*}+\Delta U P+\Delta R R+\Delta W W+\Delta A G .
$$

The value of present-day loading, $L^{*}$, can be computed from the measured present-day $P$ concentration in a lake by using equation 7 , and $L_{b g}^{*}$ can be computed using equation 11 . The rest of the terms in equation 19 were then progressively evaluated as follows.

\section{Another Lake in the Drainage Basin}

When an upstream lake is present, its contribution to increased $\mathrm{P}$ loading, $\triangle U P$, can be estimated from the calculated change in loading that has occurred at the upstream lake (if any) and the lake-retention coefficient, $R$, for the upstream lake.

$$
\Delta U P=\left(L^{*}-L_{\mathrm{bg}}^{*}\right) \cdot(1-R) .
$$

The standard error of a calculated value of $\triangle U P, S E_{\mathrm{UP}}$, is approximately

$$
S E_{\Delta \mathrm{uP}}=\left(S E_{\mathrm{L}}^{* 2}+S E_{L_{\mathrm{bg}}^{*}}{ }^{2}\right)^{1 / 2} \cdot(1-R) .
$$

In both equations 20 and 21 , all terms in the right-hand side are for the upstream lake. Though $S E_{L_{\mathrm{bg}}^{*}}$ can be estimated by equation 15 or $18, S E_{\mathrm{L}}^{*}$ has not yet been evaluated.

The standard error of the loading rate, $L^{*}$, is the result of uncertainty in both the measured lake-water $P$ concentration and the sensitivity value, $S$, in equation 7 . Previous evaluation of the unexplained variance in the values of FOR $Y$ shown in figure 2 indicat ed that a reasonable estimate of the average standard error of $S, S E_{\mathrm{S}}$, is \pm 20 percent. The standard error of the mean lake-water $P$ concentration, which usually dominates the error in $L^{*}$, can be evaluated by standard statistical methods when the number of individual measurements for a lake is large enough (generally 4 samples or more). When results for only 1 to 3 samples are available, the standard error, $S E_{(P)_{\mathrm{ss}}}$, can be estimated from the following equation (Gilliom, 1978):

$$
S E_{(\bar{P})_{s \mathrm{~s}}}=\left(\frac{0.30}{\sqrt{\mathrm{n}}}+0.20\right) \cdot(\bar{P})_{\mathrm{ss}},
$$

where $\mathrm{n}$ is the number of samples for which data are are available. This tends to somewhat overestimate errors. The standard error of $L^{*}$ can then be calculated as follows:

$$
S E_{\mathrm{L}}{ }^{*}=\left(\frac{S E_{(\bar{P})_{\mathrm{ss}}}{ }^{2}}{S^{2}}+\frac{(\bar{P})_{\mathrm{ss}}{ }^{2} \cdot S E_{\mathrm{s}}{ }^{2}}{S^{4}}\right)^{1 / 2} .
$$

\section{Residential Area Runoff}

The increased loading of $\mathrm{P}$ over the background level from single-family residential areas for lakes with only forest and residential land use in their basins, and with all near-shore dwellings served by sanitary sewers that export domestic wastewater from the drainage basin, $\Delta R R$, can now be calculated by difference using a rearrangement of equation 19 .

$$
\Delta R R=L^{*}-L_{\mathrm{bg}}^{*}-\Delta U P .
$$

The standard error of loading from residential area runoff, $S E_{\triangle R R}$, calculated by this method is a function of the standard errors in the present-day loading, the background part of the present-day loading, and increased loading from upstream lake(s). The cumulative effect of these uncertainties is calculated as follows:

$$
S E_{\triangle \mathrm{RR}}=\left(S E_{\mathrm{L}}{ }^{2}+S E_{L_{\mathrm{bg}}^{*}}{ }^{2}+S E_{\Delta \mathrm{UP}}{ }^{2}\right)^{1 / 2} .
$$

The difference method for calculating increased loading caused by residential area runoff (eq 24) is only valid for a few lakes in the Puget Sound region, because at most lakes there are other potential $P$ loadings (such as those from septic tank systems or agricultural land). For estimating $\triangle R R$ for lakes that do not meet land-use conditions required for application of equation 24 , a simple empirical relationship was developed based on increased yields (compared to background conditions) of $\mathrm{P}$ from sewered residential areas, $\triangle R R$, for four lakes in the region that meet the required conditions and have no other lakes in their drainage basins. Appropriate data for the lakes are given in table 2 .

Increased $\mathrm{P}$ yields caused by residential development $\triangle R R Y$, were calculated for each of the four lakes by use of equation 26

$$
\Delta R R Y=\frac{\Delta R R}{W S A_{\text {res }}}
$$

where $\triangle R R$ was calculated using equation 24 and $W S A_{\text {res }}$ is the area, in square kilometers, of residential land use. The mean increase in $P$ yield from developed areas in the basins of the four lakes was $7.0\left(\mathrm{~kg} / \mathrm{km}^{2}\right) / \mathrm{yr}$ 
Table 2. Physical characteristics, measured mean phosphorus concentrations, and land-use data for lakes used to evaluate phosphorus loading by residential area runoff

\begin{tabular}{|c|c|c|c|c|c|c|c|}
\hline & Lake $^{1}$ & $\begin{array}{c}\text { Watershed } \\
\text { area }^{2} \\
\text { WSA } \\
\left(\mathrm{km}^{2}\right)\end{array}$ & $\begin{array}{c}\text { Residential } \\
\text { land area } \\
W^{2} A_{\text {res }} \\
\left(\mathrm{km}^{2}\right)\end{array}$ & $\begin{array}{c}\text { Lake } \\
\text { area } \\
\text { A } \\
\left(\mathrm{km}^{2}\right)\end{array}$ & $\begin{array}{l}\text { Mean } \\
\text { depth}^{2} \\
\bar{z} \\
(\mathrm{~m})\end{array}$ & $\begin{array}{c}\text { Annual } \\
\text { runoff }^{3} \\
\text { RO } \\
(\mathrm{m}) \\
\end{array}$ & $\begin{array}{c}\text { Measured total P } \\
\text { concentration } \\
(\overline{\mathbf{P}})_{\mathrm{ss}} \\
(\mu \mathrm{g} / \mathrm{L})\end{array}$ \\
\hline 1 & Angle & 2.1 & 1.6 & 0.41 & 7.6 & 0.46 & $16 \pm 4$ \\
\hline 2 & Burien & 1.0 & .82 & .18 & 4.0 & .46 & $19 \pm 7$ \\
\hline 3 & Echo & 1.2 & 1.1 & .05 & 4.3 & .46 & $20 \pm 7$ \\
\hline 4 & Star & 1.5 & .61 & .14 & 7.6 & .51 & $13 \pm 5$ \\
\hline
\end{tabular}

'Numbers refer to locations in fig. 1 .

'Bortleson and others (1976).

'Gladwell and Mueller (1967).

${ }^{4}$ All reported concentration are total $P$ measured in epilimnion waters ( 1 -meter depth) during summer stratification, $(\bar{P})$ ss. All values are from Gilliom (1978), as summarized from data collected by other researchers.

with a standard deviation of $2.9\left(\mathrm{~kg} / \mathrm{km}^{2}\right) / \mathrm{yr}$. The values of $\triangle R R$ for other lakes in the region can be estimated from these data using the following equation:

$$
\Delta R R=7.0 \cdot W S A_{\text {res }}
$$

If calculated by equation 27 , the standard error of $\triangle R R$ for a particular lake is mainly a function of the uncertainty in $\triangle R R Y(\triangle R R Y=7.0$ in eq 27), which. for the four lakes studied, has a standard error, $S E \triangle_{\mathrm{RRY}}$, of $2.9\left(\mathrm{~kg} / \mathrm{km}^{2}\right) / \mathrm{yr}$. The validity of this error estimate for lakes in areas with annual runoff different from that $(0.46$ to $0.51 \mathrm{~m}$ ) of the four lakes evaluated is unknown. For evaluations of $\triangle R R$ for lakes much outside this range of runoff, the potential for error is probably greater and may be systematic (consistently high or low). The author suggests that, until more information is available, a reasonable but subjective estimate of $S E \Delta_{\text {RRY }}$ for lakes in areas with annual runoff less than $0.3 \mathrm{~m}$ or greater than $0.7 \mathrm{~m}$ is \pm 75 percent (as opposed to the equivalent of \pm 41 percent when annual runoff is 0.3 to $0.7 \mathrm{~m}$ ). Thus, for lakes in areas with annual runoffs of from 0.3 to $0.7 \mathrm{~m}$, use

$$
S E_{\triangle_{\mathrm{RR}}}=2.9 \cdot W S A_{\text {res }}=0.41 \cdot \Delta R R,
$$

and, for lakes in areas with annual runoff less than $0.3 \mathrm{~m}$ or greater than $0.7 \mathrm{~m}$, use

$$
S E_{\triangle_{\mathrm{RR}}}=0.75 \cdot \Delta R R \text {. }
$$

Values of $\Delta R R$ from equation 27 can be compared to data published in other reports by converting estimated values of $\triangle R R$ to the equivalent yield of total $\mathrm{P}$ from residential areas. The value of $\triangle R R Y$ was added to $F O R Y$, the background yield, and then the sum was increased 20 percent (to approximate total $\mathrm{P}$ loading) providing an estimate of total $P$ yield from residentially developed land. Resulting estimated yields of total $\mathrm{P}$ from residential areas with annual runoffs from 0.1 to 1.5 $\mathrm{m}$ range from 9 to $30\left(\mathrm{~kg} / \mathrm{km}^{2}\right) / \mathrm{yr}$. The variation is caused by differences in the background yield for different annual runoff. These yield rates are fairly low compared to reported values for other regions, but they represent increases above background yields ranging from a factor of 1.3 for high-runoff areas to 7.7 for low-runoff areas. This range compares reasonably with data from a number of North American studies reported by Uttormark and others (1974), which suggest that residential and urban areas typically yield 2 to 8 times more $P$ than forested areas. In addition, many of the areas represented in the study by Uttormark and his colleagues were more heavily developed than the single-familyresidence areas evaluated in this study. More precise validation of the empirical relationship (eq 27) for estimating increased yield caused by residential development can best be accomplished by comparison with directly measured $\mathrm{P}$ yields for this region as those data become available in the future.

\section{Nearshore Septic Tank Systems}

Phosphorus loading to a lake from nearshore septic tank systems, $\Delta W W$, can now be calculated by difference for lakes that are unaffected by agricultural land use.

$$
\Delta W W=L^{*}-L_{\mathrm{bg}}^{*}-\Delta U P-\Delta R R .
$$

The standard error of $\Delta W W, S E_{\Delta W W}$, can be calculated using equation 31 , which sums the effects of uncertainties in total present-day P loading and all other previously evaluated sources of loading.

$$
S E_{\Delta \mathrm{wW}}=\left(S E_{\mathrm{L}}^{* 2}+S E_{\mathrm{L}_{\mathrm{bg}}^{*}}^{{ }^{2}}+S E_{\Delta \mathrm{UP}^{2}}+S E_{\Delta \mathrm{RR}}^{2}\right)^{1 / 2} .
$$


Guidelines for estimating all terms in the right-hand side of this equation were discussed in the preceding section.

For estimating loading from sept ic tank systems for lakes that have agricultural land use in their basins, an empirical regional relationship between $\Delta W W$ and the numbers of nearshore dwellings around lakes was developed (the difference method of equation 30 cannot be used). Values of $\Delta W W$ were calculated from equation 30 for a sample of 24 lakes that have no other lakes in their basins and are not influenced by agricultural land use. Appropriate data for these lakes are given in table 3.

Phosphorus loading from septic tank systems may be partly dependent on the age of the system (for an example, see Dudley and Stephenson, 1973). To empirically test the influence of this factor, model-estimated values of $\Delta W W$ (eq 30) were evaluated for correlation with numbers of nearshore dwellings (generally with in 75 $m$ of the lake) at respective lakes at 10-year int ervals from 1940 to 1970 . Values of $\Delta W W$ for the 24 lakes in table 3 were used for this analysis, and the appropriate numbers of nearshore dwellings, as estimated from cultural data on U.S. Geological Survey topographic maps, are given in table 4. When such data were not available for the exact years necessary, linear interpolations were made. The numbers of dwellings represent all homes, including those that are used seasonally, and each dwelling does not necessarily have a septic tank system. Other buildings, such as garages and barns, may also be included, but the author's experience around these lakes suggests that this will have a small effect on the total count. Despite short-

Table 3. Physical characteristics, measured mean phosphorus concentrations, and land-use data for 24 lakes used to evaluate phosphorus loading from nearshore septic tank systems.

\begin{tabular}{|c|c|c|c|c|c|c|c|}
\hline & Lake $^{1}$ & $\begin{array}{c}\text { Watershed } \\
\text { area }^{2} \\
\text { WSA } \\
\left(\mathbf{k m}^{2}\right)\end{array}$ & $\begin{array}{c}\text { Residential } \\
\text { land area } \\
\text { WSA } \\
\left(\mathbf{k m}_{\text {res }}^{2}\right)\end{array}$ & $\begin{array}{c}\text { Lake } \\
\text { area } \\
A \\
\left(\mathrm{~km}^{2}\right)\end{array}$ & $\begin{array}{c}\text { Mean } \\
\text { depth } \\
\bar{Z} \\
(\mathbf{m})\end{array}$ & $\begin{array}{c}\text { Annual } \\
\text { runoff }^{3} \\
\text { RO } \\
(\mathbf{m})\end{array}$ & $\begin{array}{c}\text { Measured total P } \\
\text { concentration } \\
(\overline{\mathbf{P}})_{\text {ss }} \\
(\mu \mathrm{g} / \mathrm{L})\end{array}$ \\
\hline 5 & Alice & 0.62 & 0.06 & 0.13 & 2.5 & 0.63 & $12 \pm 4$ \\
\hline 6 & Beaver 1 & 1.0 & .04 & 0.5 & 6.7 & .51 & $16 \pm 8$ \\
\hline 7 & Boren & 2.8 & .67 & .07 & 5.5 & .51 & $16 \pm 5$ \\
\hline & Bosworth & 3.7 & .37 & .45 & 11 & .51 & $4 \pm 2$ \\
\hline 9 & Carney & 1.2 & .05 & .17 & 3.7 & .51 & $11 \pm 6$ \\
\hline 10 & Crescent & 3.1 & .03 & .20 & 4.9 & .51 & $17 \pm 6$ \\
\hline 11 & Desire & 3.5 & .36 & .29 & 4.0 & .51 & $23 \pm 6$ \\
\hline 12 & $\begin{array}{l}\text { Devils } \\
\text { (Snohomish County) }\end{array}$ & y) .52 & .06 & .05 & 7.0 & .51 & $11 \pm 6$ \\
\hline 13 & Echo & .60 & .06 & .07 & 5.2 & .51 & $15 \pm 8$ \\
\hline 14 & Gravelly & 1.7 & 1.1 & .65 & 12 & .38 & $16 \pm 6$ \\
\hline 15 & Jackson & .83 & .02 & .07 & .46 & .51 & $15 \pm 8$ \\
\hline & Joy & 2.0 & .34 & .44 & 7.0 & .56 & $7 \pm 4$ \\
\hline 17 & Loma & .39 & .07 & .09 & 3.4 & .31 & $26 \pm 9$ \\
\hline 18 & Margaret & 6.2 & .06 & .22 & 5.2 & .51 & $10 \pm 4$ \\
\hline 19 & Morton & 1.0 & .16 & .28 & 4.6 & .51 & $19 \pm 4$ \\
\hline 20 & $\begin{array}{l}\text { Number } \\
\text { Twelve }\end{array}$ & 1.3 & .05 & .18 & 4.0 & .51 & $23 \pm 9$ \\
\hline & Pipe & 1.3 & .15 & .22 & 8.2 & .51 & $20 \pm 4$ \\
\hline 22 & Retreat & 5.7 & .29 & .21 & 7.0 & .51 & $19 \pm 5$ \\
\hline & $\begin{array}{l}\text { Roesiger } \\
\text { (north arm) }\end{array}$ & 5.1 & .65 & .08 & 15 & .76 & $15 \pm 6$ \\
\hline 24 & Spring & 1.8 & .14 & .28 & 5.8 & .51 & $15 \pm 6$ \\
\hline & Steel & .98 & .65 & .19 & 7.3 & .63 & $15 \pm 6$ \\
\hline & Stickney & 9.2 & 2.0 & .08 & 4.6 & .51 & $20 \pm 4$ \\
\hline 27 & Walker & 1.3 & .13 & .05 & 9.5 & .51 & $16 \pm 6$ \\
\hline 28 & Wilderness & 1.7 & .03 & .28 & 6.4 & .51 & $28 \pm 6$ \\
\hline
\end{tabular}

'Numbers refer to location in fig. 1 .

'Bortleson and others (1976).

'Gladwell and Mueller (1967).

${ }^{4}$ All reported concentrations are total $P$ measured in lake-surface waters $\left(1 \mathrm{~m}\right.$ depth) during summer stratification, $(\bar{P})_{\text {Ss. }}$ All values are from Gilliom (1978), as summarized from data collected by other researchers, except for values for Roesiger Lake (north arm), which are from Bortleson and others (1976). 
Table 4. Numbers of nearshore dwellings at 24 lakes, and model-calculated phosphorus loadings from septic tank systems $(\Delta W W)$

\begin{tabular}{|c|c|c|c|c|c|c|}
\hline \multirow{2}{*}{\multicolumn{2}{|c|}{ Lake }} & \multicolumn{4}{|c|}{$\begin{array}{c}\text { Number of } \\
\text { nearshore dwellings }\end{array}$} & \multirow{2}{*}{$\begin{array}{c}\text { Calculated } 1 \\
\text { value of } \\
\Delta W W \\
(\mathrm{~kg} / \mathrm{yr}) \\
\end{array}$} \\
\hline & & 1940 & 1950 & 1960 & 1970 & \\
\hline 5 & Alice & 0 & 30 & 32 & 54 & -1 \\
\hline 6 & Beaver & 1 & 0 & 5 & 7 & 13 \\
\hline 7 & Boren & 0 & 0 & 11 & 22 & -3 \\
\hline 8 & Bosworth & 0 & 28 & 57 & 81 & -33 \\
\hline 9 & Carney & 0 & 14 & 24 & 34 & -2 \\
\hline 10 & Crescent & 0 & 0 & 7 & 33 & 10 \\
\hline 11 & Desire & 12 & 39 & 46 & 60 & 28 \\
\hline 12 & $\begin{array}{l}\text { Devils } \\
\text { (Snohomish }\end{array}$ & $\begin{array}{c}0 \\
\text { unty) }\end{array}$ & 1 & 10 & 19 & -1 \\
\hline 13 & Echo & 0 & 3 & 12 & 30 & 2 \\
\hline 14 & Gravelly & 22 & 49 & 74 & 91 & 15 \\
\hline 15 & Jackson & 0 & 0 & 4 & 27 & 4 \\
\hline 16 & Joy & 14 & 55 & 68 & 69 & -5 \\
\hline 17 & Loma & 0 & 10 & 19 & 47 & 3 \\
\hline 18 & Margaret & 0 & 0 & 17 & 52 & -17 \\
\hline 19 & Morton & 0 & 4 & 40 & 77 & 10 \\
\hline 20 & $\begin{array}{l}\text { Number } \\
\text { Twelve }\end{array}$ & 11 & 27 & 28 & 34 & 14 \\
\hline 21 & Pipe & 22 & 43 & 51 & 60 & 17 \\
\hline 22 & Retreat & 45 & 47 & 52 & 63 & 23 \\
\hline 23 & $\begin{array}{l}\text { Roesiger } \\
\text { (north arm) }\end{array}$ & 21 & 77 & 142 & 189 & 21 \\
\hline 24 & Spring & 0 & 1 & 14 & 36 & 7 \\
\hline 25 & Steel & 30 & 45 & 57 & 90 & 4 \\
\hline 26 & Stickney & 0 & 14 & 23 & 33 & -4 \\
\hline 27 & Walker & 0 & 10 & 19 & 29 & 3 \\
\hline 28 & Wilderness & 27 & 49 & 49 & 50 & 37 \\
\hline
\end{tabular}

Negative values for $\Delta W W$ indicate that the model-estimated phosphorus loading from background sources and residential area runoff was greater than the total loading calculated from the measured lake-water concentration of total phosphorus.

comings, the number of dwellings determined by this method is a useful empirical indicator of the number and average age of septic tank systems actually in operation at a particular lake. Even more useful, though not feasible to collect within the scope of this study, would be the number of dwellings with septic tank systems actually in use on a year-round basis for the period concerned.

A nalysis of the available data revealed a significant correlation $(\alpha=0.05)$ between calculated septic system $P$ loadings, $\triangle W W$, and numbers of nearshore dwellings present in 1940 at the 24 lakes evaluated. A substantially poorer, but significant, correlation was found between $\Delta W W$ and numbers of dwellings in 1950 , and no significant correlation was found between $\Delta W W$ and numbers of dwellings in 1960 or 1970 . For lakes with no 1940 $\mathrm{d}$ wellings, the average value of $\Delta W W$, as determined by the model (eq 30), was about zero. The apparent effects on loading of other variables, such as geology and soil type, were inconsistent and could not be distingguished with the available data. The data suggest, however, that the age of a septic tank system affects the amount of $P$ it contributes to an adjacent lake. Possible reasons (singly or in combination) for this occurrence include (1) the gradual clogging of a drainfield, resulting in surfacing of effluent and overland flow to a lake, (2) a deteriorating capacity of soil between a drainfield and a lake to remove and fix $P$, (3) a long travel time for contaminated ground water to move from a drainfield area to a lake, and (4) inferior installation standards for the older systems. Gradual increases in loadings from aging nearshore residential development around many Puget Sound region lakes is a possibility that should be investigated.

Equation 32, based on 1940 dwellings, explains 36 percent of the sample variance $\left(r^{2}=0.36\right)$.

$$
\Delta W W=0.68 \cdot(\text { number of } 1940 \text { dwellings })-0.20 .(32
$$

Figure 3 shows the regression analysis and standard errors of estimates of $\Delta W W$ from equation 32. Standard error estimates from figure 3 are valid for most lakes in the Puget Sound region. The variability in the data shown in figure 3 is due to errors in all terms used to calculate $\Delta W W$ in equation 30 , in addition to variance resulting from environmental factors such as soils, geology, ground water, and annual precipitation or runoff. Though there appear to be no systematic differences in variability related to annual runoff in the area of a lake, the lakes in table 3 represent a fairly restricted range of runoff conditions. Equation 32 may tend to overestimate $\Delta W W$ for lakes in the drier parts of the region where $\mathrm{RO}$ is less than $0.30 \mathrm{~m} / \mathrm{yr}$ and under estimate $\Delta W W$ for lakes where runoff exceeds $0.70 \mathrm{~m} / \mathrm{yr}$; however, relatively few lakes whose septic systems are presently a possible $\mathbf{P}$ source are located in these areas.

Septic system loadings estimated from equation 32 , considered on a per dwelling basis, are not directly comparable to measured values from field studies reported in available literature, because 1940 dwellings have an uncertain cause-effect relationship to present-day conditions. A general comparison, however, is useful for detecting gross discrepancies between the model and reality. Data from Uttormark and others (1974) indicate a per capita $P$ production in domestic waste-water of about $1.5 \mathrm{~kg} / \mathrm{yr}$. If each dwelling houses an average of 2.5 persons (Donald Pethick, Puget Sound Council of Governments, oral commun., 1980), the average P production per dwelling is about $3.8 \mathrm{~kg} / \mathrm{yr}$. Data from several studies reviewed and discussed by Gilliom.(1978) indicate that, for conditions in the Puget Sound region, 60 to 98 percent of the $P$ entering a septic tank system will 


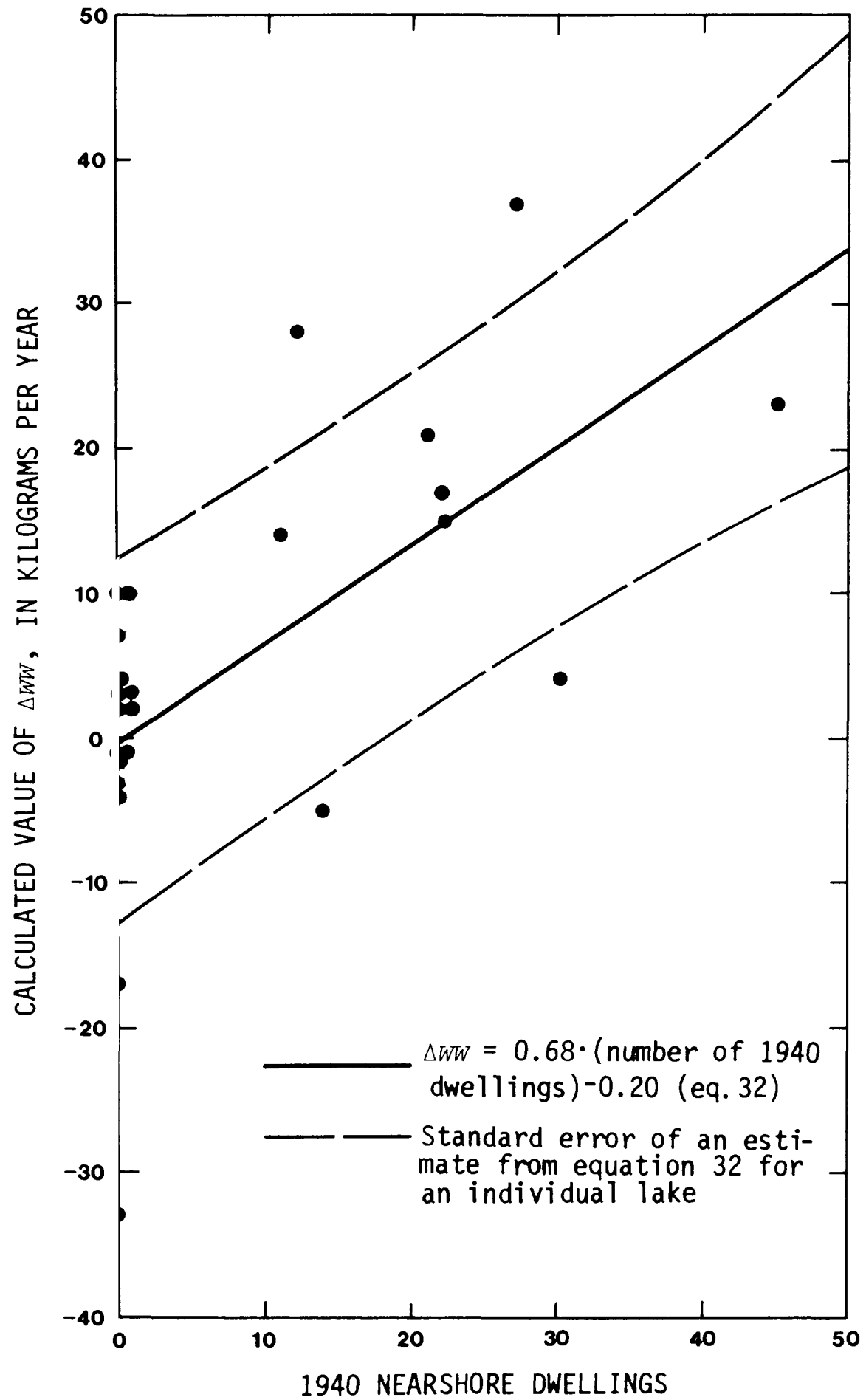

Figure 3. Relationship between calculated phosphorus loading from nearshore septic tank systems ( $\triangle W W$ ) and number of nearshore dwellings at 24 lakes in 1940. 
probably be retained by soil in or near the drainfield over a period of many years (the actual period may vary greatly). If a range of soil-retention coefficients of 0.60 to 0.98 is assumed, potential $P$ inputs to a lake from each nearshore septic tank system would range from 0.1 to 1.5 $\mathrm{kg} / \mathrm{yr}$. Equation 32, in comparison, attributes about 0.7 $\mathrm{kg} / \mathrm{yr}$ to each 1940 nearshore dwelling. This can be increased by 20 percent to approximate total $P$ loading, which would be $0.8 \mathrm{~kg} / \mathrm{yr}$. Thus, the range of theoretical values for $\triangle W W$ per dwelling brackets the value indicated by equation 32 . Equation 32 suggests an average soil-retention coefficient of about 80 percent when based on 1940 dwellings. The retention coefficient would be much higher ( $>95$ percent) if calculated from presentday dwellings.

\section{Agricultural Land}

Increased $P$ loading caused by agricultural land use can now be calculated by difference, with other loadings estimated independently.

$$
\Delta A G=L^{*}-L_{\mathrm{bg}}^{*}-\Delta U P-\Delta R R-\Delta W W .
$$

The standard error of estimated loadings from agricultural land can be calculated using equation 34 , which combines the effects of uncertainties in all terms in the right-hand side of equation 33 .

$$
\begin{aligned}
S E \Delta A G & =\left(S E_{\mathrm{L}}{ }^{2}+S E_{L_{\mathrm{bg}}^{*}}{ }^{2}+S E \Delta \mathrm{UP}^{2}\right. \\
+ & \left.S E \Delta{ }_{\mathrm{RR}}{ }^{2}+S E \Delta \mathrm{WW}^{2}\right)^{1 / 2} .
\end{aligned}
$$

Methods for estimating the values of terms in equation 34 were discussed earlier.

Because of the extreme variability in $P$ yields from agricultural land, depending on the type of agriculture, intensity, and other factors, no attempt was made either to develop a regional empirical relationship for estimating increased loadings from agricultural areas or to compare values of $\triangle A G$ from equation 33 with published data. Such a comparison should be made, however, for each individual lake evaluated. To make the comparison, yield from agricultural land can be calculated from $\triangle A G$ using equation 35 .

$$
A G Y=\frac{\Delta A G}{W S A_{\mathrm{ag}}}+F O R Y,
$$

where $A G Y$ is the annual rate of yield in kilograms per square kilometer, and $W S A_{\text {ag }}$ is the area of agricultural land in square kilometers. This calculated yield can be compared to published data for similar agricultural areas to qualitatively evaluate the reasonableness of estimates.

\section{APPLICATION OF PHOSPHORUS-LOADING RELATIONSHIPS AND THE LAKE MODEL}

The phosphorus-loading relationships derived in this study and the previously developed lake model can be combined to make several types of calculations that are useful for evaluating (1) the sensitivity of the water quality of a lake to increases in P loading. (2) the background $P$ level of a lake and the cumulative impacts of drainage basin development on nonpoint source loading, and (3) the amounts of loading increases from specific nonpoint sources. These assessments are most appropriate in the planning stages of water-quality management for such purposes as establishing goals for lake quality, setting priorities for management efforts, and guiding the design of detailed studies.

In this section, purposes and procedures for method and applications are summarized, following a discussion of their general limitations and reliability. For an example of how the entire assessment approach can be applied to lakes in a particular area, see Gilliom (1982).

\section{General Limitations}

Specific restrictions that pertain to individual relationships developed in this study, which should be carefully considered in making calculations, were discussed in earlier sections describing method derivation. There are some important general limitations, however, that influence how these relationships and resulting estimates should be used, and for which lakes the results are valid.

Ironically, models that utilize relatively simple calculations, such as the set of relationships described in this report, are commonly misused in application because they do appear simple. The natural systems that models represent are usually complex, and the application of a simple model must be accompanied by an especially careful analysis of model reliability, available data, and professional insights regarding whether model assumptions and estimates are reasonable. Therefore, persons who are knowledgeable about lakes and lake behavior can best evaluate the potential problems involved in applying the relationships developed in this study. In most cases, managers or planners should rely on a water-quality specialist to provide them with numerical estimates and reliability evaluations, and begin their role as users of the information at that point.

Important general limitations on the applications of methods developed in this study result because $P$ loadings were indirectly estimated from $P$ concentrations using a simplified lake model based on an annual time 
scale. The lake model and the loading relationships are suitable only for estimates of long-term average conditions. None of the methods discussed in this report is legitimate for evaluating transient or local (one part of a lake) pollution problems. Furthermore, statistical relationships between $P$ loadings and land uses are directly influenced by (1) the type of lakes included in the data base used for method development, (2) the environmental characteristics of the region being investigated, and (3) the type of P-concentration measurements used to calculate loading. Estimates of loadings from these relationships are strictly valid only for lakes in the study area that stratify during the summer and that are in localities where runoff does not far exceed 1.5 meters. Their use for other lakes must be carefully justified. Though the relationships between land-use and $\mathrm{P}$ loading are not transferrable to lakes that are not in the Puget Sound region or a similar environment, the general approach described for evaluating loadings might be successfully used in other regions that also have many lakes.

\section{Method Reliability}

This study has placed emphasis on deriving standard errors for all $\mathrm{P}$-concentration and loading estimates, and these standard errors form the cornerstone for a comprehensive uncertainty analysis. Though some loading estimates may be so uncertain that they cannot be used even if no better alternatives are available. decisions related to water-quality management (especially in planning stages) usually must be made based on the best information available within practical constraints such as time and cost. Standard-error estimates are a basis for comparing the reliability of various assessment methods and judging their relative value. Standard error estimates are also valuable for identifying where further study is needed, and careful evaluation of the reasons for large standard errors can often lead to efficient ways to reduce uncertainty.

\section{Typical Standard Errors}

To give the reader a specific understanding of the magnitude of standard errors characteristic of the methods described, example error calculations were made for 14 selected lakes included in an earlier report by Gilliom (1983). All error calculations wee made according to the procedures described in this report. Each of the 14 lakes had apparent present-day P loading that was greater than estimated background loading by more than 50 percent. Table 5 shows percent standard errors in loading estimates for the lakes; errors for cultural sources that accounted for less than 25 percent of the cumulative increase in loading above background levels are not shown. For all nonbackground loadings, standard errors are shown for estimates based only on available P-concentration data for the lakes, and for estimates based on improved P-concentration data. With only the available data, the standard error in the estimated mean $P$ concentrations of the lakes in table 5 was generally \pm 30 to \pm 50 percent of the mean. For the purpose of comparison, the author assumed that an improved data base resulting from a modest data-collection effort would facilitate reduction of the standard error in lakeconcentration values to \pm 10 percent of the mean.

The data in table 5 suggest that background $P$ loading is often estimated with a standard error of \pm 20 to \pm 30 percent and almost always less than 50 percent. Background loadings for most Puget Sound region lakes are estimated with a standard error averaging about \pm 25 percent. Percent standard errors for estimated presentday loadings can be either less than or greater than those for background loading. depending mainly on the a mount of uncertainty associated with the mean presentday $P$ concentration in a lake. On the basis of available data only, most standard error values for present-day loadings are in the range of \pm 40 to \pm 50 percent. The loadings calculated from the more precise estimates of mean lake concentration have a standard error of only about \pm 20 percent.

Standard errors in estimated cumulative loading increases and individual nonpoint sources reflect the combined uncertainties in background loadings and present-day loadings. Standard errors of estimated cumulative loading increases for lakes in table 5 were usually in the \pm 50 to \pm 100 percent range when derived from available data on lake P concentrations. Improved concentration estimates would reduce these standard errors substantially, with most declining to the \pm 30 to \pm 70 percent range (see table 5). Standard error errors in estimates of loadings from major individual $\mathbf{P}$ sources for lakes are generally similar to errors in cumulative loading increases if there is only one major $P$ source. For lakes with two or more major $P$ sources, the potential for errors in estimating loadings from these sources is greater. For example, Armstrong Lake in table 5 receives large amounts of $P$ from both agricultural land and nearshore septic tank systems. Based on available data, the standard error in the loadings from each of these sources is about \pm 200 percent. With the improved concentration estimate, the standard error in agricultural $P$ loading was reduced, but not enough to change the value reported (table 5). The standard error in the loading from septic systems is fixed according to the regression relationship shown in figure 3 . In general, loading increases from small $P$ sources (about 25 percent of background loading or less), as well as all loading increases for lakes where more than two 
Table 5. Percent standard errors in phosphorus loading estimates for 14 selected lakes evaluated by Gilliom (1983)

\begin{tabular}{|c|c|c|c|c|c|c|c|}
\hline \multirow[b]{3}{*}{ Lake } & \multirow[b]{3}{*}{ Background } & \multicolumn{5}{|c|}{ Percent standard errors in phosphorus loading estimates } & \\
\hline & & \multirow[b]{2}{*}{$\begin{array}{c}\text { Present- } \\
\text { day }^{1}\end{array}$} & \multirow{2}{*}{$\begin{array}{c}\text { Cumulative } \\
\text { increase in } \\
\text { loading above } \\
\text { background } \\
\text { level }\end{array}$} & \multicolumn{4}{|c|}{ Individual sources of loading increase } \\
\hline & & & & $\begin{array}{c}\text { Upstream } \\
\text { lakes }\end{array}$ & $\begin{array}{c}\text { Residential } \\
\text { runoff }\end{array}$ & $\begin{array}{c}\text { Septic } \\
\text { systems }\end{array}$ & Agriculture \\
\hline Anderson & 60 & $50(20)$ & $70(30)$ & - & - & - & $70(30)$ \\
\hline Armstrong & 30 & $40(20)$ & $100(60)$ & - & - & $200(200)$ & $200(200)$ \\
\hline Beaver & 30 & $40(20)$ & $100(70)$ & - & - & - & $100(70)$ \\
\hline Big & 20 & $40(20)$ & $70(50)$ & $100(60)$ & $\ldots$ & - & $80(60)$ \\
\hline Cassidy & 30 & $40(20)$ & $60(40)$ & - & - & - & $60(40)$ \\
\hline $\begin{array}{c}\text { Cranberry } \\
\text { (Skagit County) }\end{array}$ & 100 & $40(20)$ & $300(200)$ & - & - & - & $300(200)$ \\
\hline Howard & 40 & $40(20)$ & $70(50)$ & $\ldots$ & $\ldots$ & $70(50)$ & - \\
\hline Loma & 30 & $70(20)$ & $200(60)$ & - & - & $200(60)$ & - \\
\hline Lone & 70 & $50(20)$ & $50(30)$ & - & - & - & $60(30)$ \\
\hline McMurray & 30 & $40(20)$ & $100(60)$ & - & - & - & $100(70)$ \\
\hline Pass & 50 & $40(20)$ & $60(30)$ & - & $\ldots$ & $\ldots$ & $60(30)$ \\
\hline Shoecraft & 40 & $30(20)$ & $90(70)$ & - & - & $90(80)$ & - \\
\hline Stevens & 20 & $40(20)$ & $100(60)$ & - & $40(40)$ & $200(100)$ & - \\
\hline Weallup & 30 & $60(20)$ & $100(60)$ & $100(60)$ & - & - & - \\
\hline
\end{tabular}

IValues in parentheses are percent standard errors that would result if the standard error in the mean lake-water concentration of phosphorus was \pm 10 percent for lakes, reduced from the present level of \pm 30 to \pm 50 percent

major nonpoint $\mathbf{P}$ sources are present, are estimated with standard errors of \pm 100 percent or greater (loading by residential area runoff is an exception).

\section{Relative Reliability}

Different methods for estimating lake $\mathbf{P}$ loadings (methods developed in this study and others) ideally should be evaluated by comparing the reliability and costs associated with each possible method. Unfortunately, as noted by Reckhow (1979), little is known about the actual uncertainties associated with different $\mathbf{P}$ loading assessment methods. Until we know more about the magnitude and causes of these uncertainties, a preliminary rating system may prove useful for comparing the methods developed in this study with other possible methods for estimating loadings. For the purposes of this study, a simple relative scale for rating reliability was devised based on the general reliability of P-loading assessment methods that are more common than those developed here.

A rating of high reliability should correspond to our most reliable method. For estimating $P$ loading, the best method is generally direct measurement of flow and $P$ concentration of inflow streams. Though the total loading by an inflowing stream might often be measured with a standard error of \pm 10 to \pm 20 percent by a fairly extensive data-collection effort (Reckhow, 1978), the break- down of this loading according to the various land uses in the drainage basin involves much greater error. Errors may also be substantially greater than \pm 20 percent if a stream is small and flows intermittently, or if long-term loading is being estimated from measured data for only one year. Any estimate of $P$ loading from a particular land use with a standard error of less than \pm 50 percent should probably be considered highly reliable.

The next most reliable approach to estimating $P$ loadings for a particular lake is probably the use of empirical relationships between land uses and loadings based on extensive measurements of loadings from representative land uses in the region where the lake is located. An example of this approach is summarized by Sonzogni and others (1980) for the Great Lakes region. This approach is probably typified by standard errors in the \pm 25 to \pm 100 percent range, though this has never been rigorously assessed to this author's knowledge. This approach, in fact, may often be better than direct measurements at a particular lake if the study period is short or if great care is not taken in the application of the measurement data. In general, loading estimates with standard errors in the \pm 50 to \pm 100 percent range should probably be considered moderately reliable.

Any loading estimate with an associated standard error greater than 100 percent has a low relative reliability. A low reliability rating is probably typical of a loading estimate using a sparse data base of measured $\mathbf{P}$ 
loadings for the region in which the study lake is located, or using data from another region or a nationwide data base.

The reliability rating system described above is summarized in table 6 . Though these reliability ratings are preliminary and general in nature, they may help the water-quality manager to quickly judge the value of various loading estimates. Estimates with a high reliability can usually be improved only at a high cost and often not significantly. Estimates with a moderate reliability may be significantly improved by direct measurements of loadings to the lake being evaluated. Estimates with a low reliability often must be improved to be of significant use for management. They may be improved by such approaches as developing an extensive regional data base for relating specific land uses to P-loading rates, or by direct measurement of loadings at the lake under investigation.

Table 6. Relative reliability ratings for phosphorus-loading estimates

\begin{tabular}{lc}
\hline $\begin{array}{c}\text { Standard error in } \\
\text { loading estimate }\end{array}$ & Relative reliability \\
\hline Less than \pm 50 percent & High \\
From \pm 50 to \pm 100 percent & Moderate \\
Greater than \pm 100 percent & Low \\
\hline
\end{tabular}

The relative reliability of methods developed in this study can be summarized using the rating system shown in table 6 and the standard error values shown in table 5. Background $\mathrm{P}$ loadings can be estimated with a high degree of reliability for most lakes. With a modest datacollection effort, present-day loading can also be estimated with a high reliability for all lakes. Major cumulative increases in $\mathrm{P}$ loading due to land-use changes in a lake's drainage basin are usually estimated with a moderate reliability, though a high degree of reliability is often possible if the uncertainty in the mean lake-water concentration of $P$ is reduced to a standard error of \pm 10 to \pm 15 percent. Cumulative loading increases that are small relative to background loading will generally be estimated with a low or moderate reliability. Standard errors in estimating loading increases caused by individual land uses are highly influenced by the magnitude of the loading, the number of major $P$ sources present at a lake, and the reliability of the present-day P-concentration estimate for the lake. In general terms, table 5 indicates that the standard error is often in the moderate to high reliability range for a $\mathbf{P}$ source that is the only major development-related source for a lake. If more than two major $P$ sources are important for a lake, all loading increases associated with individual land uses are usually estimated with a low reliability. In addition, all small loading increases can usually be estimated with only a low relative reliability using the methods described in this report. However, it should be noted that for small sources, all available methods for estimating $P$ loadings are probably subject to larger percent errors than discussed earlier. Fortunately, small sources of $P$ loading are generally less important to assess than large sources for lake-management purposes.

\section{Application I: Rating of Water-Quality Sensitivity}

\section{Management Applications}

The lake $P$ model used in this study is useful for computing a measure of a lake's sensitivity to degradation by future increases in $\mathrm{P}$ loading. Each lake has a different sensitivity to water-quality degradation by such loadings, depending mainly upon the capability of the lake to dilute and flush $P$, and to trap $P$ in bottom sediments when it settles along with particulate matter. A deep lake that has a large volume of water inflow each year has a high capability to dilute and flush $P$, and to trap $P$ in bottom sediments on a long-term. whole-lake basis. Conversely, a shallow lake with a small inflow rate has a relatively low capability to dilute and flush $P$, and $P$ that settles to the bottom is more likely to be recycled to the lake water because bottom sediments are near the lake surface where water is more turbulent. Therefore, shallow lakes with poor flushing tend to be more vulnerable to degradation that are deep lakes with large inflow volumes. Ranking the lakes on the basis of their relative sensitivity to increased $P$ loadings, which can be done quickly for many lakes, is useful for setting priorities for management and research efforts. Such an assessment can be combined with a planner's evaluation of development potential to rate the overall susceptibility of a lake to degradation.

\section{Procedure}

The relationship between an increase in the steadystate $\mathbf{P}$ loading to a lake and the corresponding increase in average $P$ concentration is given by the lake-sensitivity coefficient, $S$, which can be calculated using equation 9 . The average standard error of $S$ is about \pm 20 percent, as discussed earlier, but for the general rating system suggested below this uncertainty is of small importance.

Calculated values of $S$ (a constant for each lake) indicate approximate changes in $P$ concentration that are predicted to result from a $1-\mathrm{kg} / \mathrm{yr}$ increase in loading to the lake. Table 7 shows a relative rating system for lake 
sensitivity that was developed on the basis of a $10-\mathrm{kg} / \mathrm{yr}$ increase in loading. A standard increase of $10-\mathrm{kg} / \mathrm{yr}$ was chosen because it is easy to use and is well within the range of feasible increases in loading due to typical largescale land-use changes. Converting $1.5 \mathrm{~km}^{2}$ of forest land in a lake's basin to residential land use, for example, would likely result in about a $10-\mathrm{kg} / \mathrm{yr}$ increase in loading for a lake in the Puget Sound region.

ln general, lakes rated extreme or high in table 7 would usually show signs of water-quality changes visible to the casual observer if loading was increased by 10 $\mathrm{kg} / \mathrm{yr}$. Lakes rated moderate in sensitivity may, or may not, show such changes, and lakes rated low usually would not show readily visible changes.

Table 7. Criteria for rating lake sensitivity

\begin{tabular}{|c|c|}
\hline $\begin{array}{c}\text { Lake } \\
\text { sensitivity }\end{array}$ & Criteria \\
\hline $\begin{array}{l}\text { Extreme: } \\
(S \cdot 10 \geq 20)\end{array}$ & $\begin{array}{l}\text { Annual } \mathrm{P} \text { loading increase of } 10 \mathrm{~kg} \\
\text { results in a } 20 \mu \mathrm{g} / \mathrm{L} \text { or greater increase } \\
\text { in lake-water } \mathrm{P} \text { concentration. }\end{array}$ \\
\hline $\begin{array}{l}\text { High: } \\
(10 \leq S \cdot 10 \leq 20)\end{array}$ & $\begin{array}{l}\text { Annual } \mathrm{P} \text { loading increase of } 10 \mathrm{~kg} \\
\text { results in a } 10-\text { to } 20-\mu \mathrm{g} / \mathrm{L} \text { increase in } \\
\text { lake-water } \mathrm{P} \text { concentration. }\end{array}$ \\
\hline $\begin{array}{l}\text { Moderate: } \\
(3 \leq S \cdot 10 \leq 10)\end{array}$ & $\begin{array}{l}\text { Annual } \mathrm{P} \text { loading increase of } 10 \mathrm{~kg} \\
\text { results in a } 3-\text { to } 10-\mu \mathrm{g} / \mathrm{L} \text { increase in } \\
\text { lake-water } \mathrm{P} \text { concentration. }\end{array}$ \\
\hline $\begin{array}{l}\text { Low: } \\
S \cdot 10<3 \text { ) }\end{array}$ & $\begin{array}{l}\text { Annual } \mathrm{P} \text { loading increase of } 10 \mathrm{~kg} \\
\text { results in less than } 3-\mu \mathrm{g} / \mathrm{L} \text { change in } \\
\text { lake-water } \mathrm{P} \text { concentration. }\end{array}$ \\
\hline
\end{tabular}

\section{Application II: Estimation of Background Phosphorus Levels and Cumulative Impacts of Development}

\section{Management Applications}

The background (predevelopment) concentration of total $P$ in a lake is the standard against which all human-related phosphorus enrichment should be evaluated. Data for undeveloped lakes in the Puget Sound lowland indicated background concentrations of total $P$ ranging from 6 to $47 \mu \mathrm{g} / \mathrm{L}$ (Gilliom, 1981; I983). For a significant number of lakes, assumption of a regional constant value for background concentrations would be a misleading estimate. If water-quality standards were based on such an estimate, or if human impacts on lakewater $\mathbf{P}$ levels were evaluated from such an estimate, unobtainable water-quality goals or incorrect assessments of cultural impacts could result. Careful assessments of background levels provide the basis for realistic water-quality standards to accommodate different levels of natural lake-water fertility.
Perhaps most important, the cumulative impact of existing drainage-basin development can be evaluated by subtracting the estimated background (predevelopment) P-concentration from the measured, present-day (postdevelopment) concentration. Similar estimates can be made for $P$ loadings. Moreover, these estimates of impact can be made with predictable reliability so that managers can judge the value of the estimates and determine whether more data are needed. Such impact assessments can provide valuable guidance for future studies and expenditures of planning resources by identifying lakes with the greatest human-related impacts.

\section{Procedure}

The background level of loading to a lake (whet her the basin is developed or not) is estimated by assuming that the lake has a completely forested drainage basin, so that loading to the lake is only from forest-land drainage. bulk precipitation directly on the lake's surface, or another undeveloped lake. The yield of $P$ from forest land is calculated using equation 14, areal loading by bulk precipitation is a constant given by using equation 12 , and loading from an upstream lake is calculated by using equation 16 . Total background loading, the sum of these sources, is computed using equation 11 . The standard error of the estimated background loading is calculated using equation 15 when no upstream lake is present, or equation 18 when an upstream lake is present.

The background $P$ concentration of a lake can then be estimated from the loading by using the lake model in the form of equation 8 , for which $L^{*}$ is equal to $L_{\mathrm{bg}}^{*}$ and $(\bar{P})_{\mathrm{ss}}$ is thus the background concentration, $(\bar{P})_{\mathrm{bg} \text {. }}$. The standard error of such an estimate can be calculated solely as a function of uncertainty in $L_{\mathrm{bg}}^{*}$ because the variability in $L_{\mathrm{bg}}^{*}$ already incorporates variance due to the lake model. Therefore,

$$
S E_{(\bar{P})_{\mathrm{bg}}}=S E_{L_{\mathrm{bg}}^{*}} \cdot S
$$

where $S E_{L_{\mathrm{bg}}^{*}}$ is from equation 18.

The procedures for calculating the cumulative impact of existing drainage-basin development on the $P$ concentration and loading of a lake, and for calculating the standard errors of these estimates are as follows. The concentration impact is estimated from

$$
\Delta(\bar{P})_{\mathrm{ss}}=(\bar{P})_{\mathrm{ss}}-\left(\bar{P}_{\mathrm{sg}},\right.
$$

where $\Delta(\bar{P})_{\text {ss }}$ represents the increase in lake-water concentration caused by development in a lake's drainage basin, and $\left(\bar{P}_{\mathrm{ms}}\right.$ represents the measured present-day 
value of $(\bar{P})_{\text {ss }}$. The present-day mean concentration should be estimated from measurements of total $P$ in samples taken from about $1 \mathrm{~m}$ below the lake surface at mid-lake site. Samples should ideally be collected periodically ( 3 to 10 times) throughout the summer period, approximately May 15 to September 15 . Total P should be analyzed to the nearest microgram per liter $(0.001$ $\mathrm{mg} / \mathrm{L}$ ), and results for all samples should be averaged, with the standard error of the mean determined by the standard statistical method. The calculated mean value is $(\bar{P})_{\mathrm{ss}}$ and the standard error of that mean is $S E_{(\bar{P})_{\mathrm{ss}}}$ As mentioned earlier. equation 22 can be used to estimate $S E_{(}(\bar{P})_{\mathrm{ss}}$ for very small samples $(\mathrm{n}<4)$, but the error is usually overestimated. The standard error of $\Delta(\bar{P})_{\mathrm{ss}}$ can then be calculated using equation 38 .

$$
S E_{\Delta(\bar{P})_{\mathrm{ss}}}=\left(S E_{(\bar{P})_{\mathrm{ss}}^{\mathrm{m}}}{ }^{2}+S E_{(\bar{P})_{\mathrm{sg}}^{\mathrm{bg}}}^{2}\right)^{1 / 2} .
$$

The cumulative impact of development can also be expressed in terms of $\mathrm{P}$ loading $\left(\Delta L^{*}\right)$ using equations 39 and 40.

$$
\Delta L^{*}=L^{*}-L_{\mathrm{bg}}^{*},
$$

where $L^{*}$ is calculated from $(\bar{P})_{\mathrm{ss}}$ using equation 7 . Then,

$$
S E_{\triangle \mathrm{L}^{*}}=\left(S E_{\mathrm{L}^{*}}+S E_{L_{\mathrm{bg}}^{*}}{ }^{2}\right)^{1 / 2}
$$

where $S E_{\mathrm{L}}{ }^{*}$ is from equation 23 .

\section{Application III: Phosphorus Loading from Individual Land Uses}

\section{Management Applications}

The land-use phosphorus-loading relationships developed in this study allow an important advance from the simple comparison of model-estimated background concentration to present-day concentrations. The relationships allow a proportioning of the estimated cumulative impact of all land-use changes in a basin into the portions of impact caused by each general land use. This preliminary assessment of the relative importance of potential nonpoint sources of $P$ can provide valuable guidance for both regional planning and site-specific studies. From a regional point of view, such assessments show which nonpoint sources are most important to manage and thus aid in setting priorities for management and research efforts. Though individual lakes usually require site-specific studies in order to determine appropriate means to control $\mathrm{P}$ loadings, the loading estimates possible with the methods described in this report can make the study design more efficient. Such a preliminary assessment identifies the most probable major $P$ sources and, perhaps just as important, guides the investigator through a mass-balance analysis of a lake's potential loadings. This analysis can improve both sampling program design and later interpretations of data.

\section{Procedure}

Suggested guidelines for applying the land-use, phosphorus-loading relationships to lakes with different land-use situations in their drainage basins are summarized below. The reader is again cautioned that the derivation of each equation should be reviewed before its use. The following procedures are described with the assumption that background loading and the present-day loading have already been estimated.

Basin Land-Use Status 1.-Subject lake has another lake in its drainage basin.

The contribution of $\mathbf{P}$ from an upstream lake (or lakes) to increased loading should be calculated by using equation 20 and the standard error of that estimate by using equation 21 . The increases in loading caused by $P$ sources in the subject lake's immediate drainage basin (the part without other lakes) should then be assessed according to the procedures given below.

Basin Land-Use Status 2.-Forested and residential; nearshore septic tank systems are not a factor (residential areas are sewered or are remote from the lake).

The increase in loading caused by residential area runoff should be calculated using equation 24 and the standard error calculated using equation 25 . This result should be checked by comparing it with estimates from equation 27 , the regional relationship. Large deviations from results predicted by equation 27 should be carefully evaluated for possible errors in measured lake-water $P$ concentration and estimated background loading. Since there are few lakes with residential areas where septic tank systems are not potential $P$ sources, most estimates of loading from residential areas will be made as described in the next land-use category.

Basin Land-Use Status 3.-Forested and residential; nearshore septic tank systems are a possible source of $\mathrm{P}$ loading.

The loading increase caused by residential area runoff should be calculated using equation 27 and the standard error estimated by using either equation 28 or 29 , depending on the annual runoff in the drainage area of the lake. The loading from septic tank systems can then be estimated by difference using equation 30 , with equation 31 used to calculate the standard error.

Basin Land-Use Status 4.-Forested, residential, and agricultural. 
For lake-drainage basins that include forested. residential, and agricultural land, residential $P$ sources must be evaluted using regional relationships so that loading from agricultural land can be calculated by difference. Loading from residential area runoff is again estimated using equation 27. and loading from septic tank systems (if applicable) is then estimated by equation 32 with a fairly constant standard error of about 12 $\mathrm{kg} / \mathrm{yr}$. Loading from agricultural land can then be calculated using equation 33, with the standard error estimated from equation 34 .

The reasonableness of estimated loading from agricultural land can also be checked. The estimated value of $\triangle A G$ from equation 33 can be converted to equivalent areal yield using equation 35 . This yield should be compared, when possible, to published yield values for similar types of agricultural land.

\section{SUMMARY}

Control of eutrophication on a regional basis is a difficult task for local and state agencies which, because of the time and expense, can only study a few individual lakes in detail. Therefore, well-conceived management priorities and efficient study designs are especially important.

The most difficult aspect of eutrophication to assess, and yet the most critical to understand for devising control strategies, is nutrient loading. The most important nutrient is phosphorus $(P)$. Preliminary estimates of $P$ loading and individual sources of $P$ loadings can greatly aid in formulating water-quality goals and priorities for further study and in efficient design of detailed studies.

Methods developed in this study allow preliminary assessments of the sensitivity of a lake to increased $P$ loading, the cumulative impact of drainage-basin development on lake-water $P$ concentration and loading, and the contribution of individual land uses to the total increase in loading above predevelopment levels. These methods, which are summarized in the preceding section of this report, require few new data and can be applied quickly, but are best used by a water-quality specialist.

Methods designed for making preliminary estimates are usually inherently less accurate than expensive, detailed studies, but the preliminary estimates can often guide, or even eliminate the need for, the detailed studies. Compared to alternative approaches, the methods presented in this report often produce estimates that are highly or moderately reliable for major $\mathrm{P}$ sources. A comprehensive framework for computing the reliability of estimates was presented so that water-quality planners and managers can evaluate the relative value of estimates from the methods developed. The reliability analysis can greatly aid in identifying where more study is, or is not, justified.

A general characteristic of the methods for estimating $P$ loadings from individual land uses is that they cannot provide very reliable est imates for relatively small loading sources, or for individual loading sources when more than one or two major loading sources are present. Even for estimating loadings from large and dominant cultural $P$ sources (greater than 25 percent of background loading), standard errors are usually 50 to 100 percent when only available data are used. An inexpensive datacollection effort can substantially reduce the standard errors of estimates for major loading sources, often to less than 50 percent.

The methods developed in this study are intended to fill a gap between having no knowledge of $P$ loadings or their impact and performing a detailed lake-quality study. Although the methods are not directly transferable to geographic areas outside the Puget Sound region, the general approach to deriving the methods may work well in other regions with many lakes. The need for preliminary estimates early in water-quality planning is believed to be widespread, and this study may be a useful prototype for similar efforts.

\section{REFERENCES CITED}

Bortleson, G.C., Dion, N.P., McConnell, J.B., and Nelson, L.M., 1976, Reconnaissance data on lakes in Washington: Washington Department of Ecology Water-Supply Bulletin 43, v. 7, 2066 p.

Chapra, S.C., and Tarapchak, S.J., 1976, A chlorophyll $a$ model and its relationship to phosphorous loading plots for lakes: Water Resources Research, v. 12. no. 6, p. 1260-1264.

Dillon, P.J., 1974, A critical review of Vollenweider's nutrient budget model and other related models: Water Resources Bulletin, v. 10, p. 969-994.

Dillon, P.J., and Rigler, F.H., 1975, A simple method for predicting the capacity of a lake for development based on lake trophic status: Journal Fisheries Research Board of Canada, v. 32, p. 1519-1531.

Dudley, J.G., and Stephenson, D.A., 1973, Nutrient enrichment of ground water from septic tank disposal systems. Inland Lake Renewal and Shoreline Management Demonstration Project Report, Upper Great Lakes Regional Commission, $131 \mathrm{p}$.

Ellsworth, Norma, and Moodie, C.D., 1964, Nutrient inputs in rainfall at nine sites in Washington, 1962 and 1963: Washington Agricultural Experimentation Station. Interim Report Project 1670,9 p.

Gilliom, R.J., 1978. A simple model for estimating lake eutrophication impacts of watershed land use: Seattle, University of Washington, unpublished M.S. thesis, $168 \mathrm{p}$. -1981, Estimation of background loadings and concentra- 
tions of phosphorus for lakes in the Puget Sound Region, Washington: Water Resources Research, v. 17, no. 2, p. $410-420$.

1983. Lake-water quality and land-use relationships for selected lakes in the Port Townsend quadrangle. Puget Sound region, Washington: U.S. Geological Survey OpenFile Water Resources Investigation 82-684, 1 sheet.

Gilliom. R.J., Bortleson, G.C., 1983, Relationships between water quality and phosphorus concentrations for lakes of the Puget Sound region, Washington: U.S. Geological Survey Open-File 83-255. 26 p.

Gladwell, J.S., and Mueller, A.C.. 1967. Water resources atlas of the State of Washington, v. II, part B. of An initial study of the water resources of the State of Washington: Pullman, Wash. Water Research Center, 59 sheets.

Jones, J.R., and Bachmann, R.W., 1976, Prediction of phosphorus and chlorophyll levels in lakes: Journal of the Water Pollution Control Federation, v. 48, p. 2177-2182.

Larsen. D.P., and Mercier, H.T., 1976, Phosphorus retention capacity of lakes: Journal Fisheries Research Board of Canada, v. 33. p. 1742-1750.

Meyer, S.L., 1975, Data analysis for scientists and engineers: New York, John Wiley and Sons, 513 p.

Piontelli, R., and Tonolli, V., 1964. 11 tempo do residenza dele aqua lacust ri in relazione ai fenomeni di arrieehimento in sostanze immesse, con particolare riguardo al Lago Maggiore: Memorie dell 'Istituto Italiano di Idrobiologia. v. 17. p. 247-266.

Rast, Walter, and Lee, G.F., 1978, Summary analysis of the North American (U.S. portion) O.E.C.D. Eutrophication Project: Nutrient loading-lake response relationships and trophic state indices: U.S. Environmental Protection Agency, Publication EPA-600/3-78-800, 455 p.

Reckhow, K.H., 1978, Lake phosphorus budget sampling design: Paper presented at the American Water Resources Association Symposium on the Establishment of Water Quality Monitoring Programs. 1978, $26 \mathrm{p}$.

1979. Uncertainty analysis applied to Vollenweider's phosphorus loading criterion: Water Pollution Control Federation Journal, v. 51, no. 8. p. 2123-2128.

Sakamoto, M., 1966, Primary production by phytoplankton community in some Japanese lakes and its dependence on lake depth: Archiv fuer Hydrobiologie, v. 62, p. 1-28.

Schindler, D.W., 1977. Evolution of phosphorus limitation in lakes: Science, v. 195, p. 260-262.

1978. Factors regulating phytoplankt on production and standing crop in the world's freshwaters: Limnology and Oceanography, v. 23, p. 478-486.

Schindler, D.W., and Fee, E.J., 1974 Experimental lakes areas: whole lake experiments in eutrophication: Journal Fisheries Research Board of Canada, v. 31, p. 937-953.

Sonzogni, W.C., and others, 1980, Pollution from land runoff: Environmental Science and Technology, v. 14, no. 2, p. $148-153$.

Uttormark, P.D., Chapin, J.D., and Green, K.M., 1974, Estimating nutrient loadings to lakes from nonpoint sources: U.S. Environmental Protection Agency. Publication EPA-600/3/74-020, $112 \mathrm{p}$.

Vollenweider, R.A., 1968, Scientific fundamentals of the eutrophication of lakes and flowing water, with particular reference to phosphorus and nitrogen as factors in eutrophication: Paris, Organization for Economic Cooperation and Development Technical Report, PAS/CSI/68, v. 27. p. $1-182$.

1969. Moglichkeiten und grenzen elementarer modelle der Stoffbilanz von Seen: Archiv fuer Hydrobiologie, v. 66. p. $1-36$.

1976. Advances in defining critical loading levels of phosphorus in lake eutrophication: Memorie del 'Istituto Italiano di Idrobiologia, v. 33, p. 53-83.

Walker, W.W., Jr., 1980, Use of hypolimnetic oxygen depletion data as a trophic state index for lakes: Water Resources Research, v. 15, no. 6, p. 1463-1470.

Welch, E.B., and Perkins, M.A.. 1979, Oxygen deficit-phosphorus loading relation in lakes: Water Pollution Control Federation Journal, v. 51, No. 12, p. 2823-2828. 


\section{Units and Conversion Factors}

For those readers who prefer to use inch-pound units rather than metric units the conversion factors are as follows:

\begin{tabular}{rcc}
\hline Multiply SI unit & By & To obtain inch-pound unit \\
\hline meters $(\mathrm{m})$ & 3.281 & feet \\
square kilometers $\left(\mathrm{km}^{2}\right)$ & 247.1 & acres \\
kilograms $(\mathrm{kg})$ & 2.205 & pounds \\
kilograms per square & 0.0089 & pound per acre \\
kilometer $\left(\mathrm{kg} \mathrm{km}^{2}\right)$ & & \\
\hline
\end{tabular}

